\title{
Student-centred digital game-based learning: a conceptual framework and survey of the state of the art
}

\author{
Thomas E. Coleman ${ }^{1} \cdot$ Arthur G. Money ${ }^{1}$
}

Published online: 19 July 2019

(C) The Author(s) 2019

\begin{abstract}
Student-centred learning forms a major driver behind educational policy and practice in the modern day. With a drive towards embracing the possibilities of technology within the classroom, especially digital video games, it is vital to have an understanding of where such games are delivering and where their potential has yet to be explored. With this in mind, it is important to survey the existing literature to establish the level to which the promise of studentcentred learning is being delivered through digital video games. This study presents a conceptual framework based upon a systematic literature review of developments in studentcentred digital game-based learning, and seeks to establish the extent to which all tenets of student-centred learning and principles of digital game-based learning are embraced within such applications. A thematic analysis identifies the common themes of game and intervention design while integrating and conceptually linking the key concepts of student-centred learning and digital game-based learning. This leads to the development of a conceptual framework allowing classification of the literature according to common themes. Inclusion criteria include the presence of student-centred learning concepts, with a game-based focus including specifically digital video games. Inclusion was limited to papers published since 2007 . The literature analysis identifies a number of themes; these were primarily the types of player engagement: single player, mixed and multiplayer, along with principles of game design and the key tenets of student-centred learning. A preponderance of games and interventions utilising single player experiences and focusing on implementing the active learning tenet of studentcentred learning were observed. Areas relating to multiplayer engagements and the social aspects of student-centred learning such as mutual respect receive comparatively less attention in games and research. In order to fully embrace the possibilities offered by student-centred digital game-based learning, it is important not to neglect lessons learned in the development
\end{abstract}

Arthur G. Money

arthur.money@brunel.ac.uk

Thomas E. Coleman

thomasedward.coleman@brunel.ac.uk

1 Department of Computer Science, Brunel University London, Kingston Lane, Uxbridge UB8 3PH, UK 
of student-centred learning to its current state. Aspects such as peer-based learning and building relationships between students and teachers have been found important in traditional learning and must be investigated and adapted to new media, including games, as new technologies enter the educational mainstream. Further research into the effects of designing games around these multiplayer aspects, and better defining the role of teachers and educational staff in digital game-based learning, may demonstrate ways to develop and create educational experiences that better engage and prepare students.

Keywords Student-centred learning · Digital game-based learning · Serious games · Game design · Video games

\section{Introduction}

Student-centred digital game-based learning (SCDGBL) is the name given to the crossover of student-centred learning techniques, practised through primary to tertiary education (Wright 2011; Rohrbeck et al. 2003), with the use of digital video games as a vehicle for learning instead of more traditional techniques. A consensus definition (Attard et al. 2010) for studentcentred learning (SCL) identifies it as a learning approach broadly related to, and supported by, constructivist theories of learning. This approach is characterised by innovative teaching methods aiming to promote learning in communication with teachers and other learners, taking students seriously as active participants in their own learning and fostering transferable skills such as problem-solving and critical/reflective thinking (Attard et al. 2010). Greater integration of the student-centred learning approach with digital game-based learning (DGBL) may provide opportunities to both further improve learning and build upon students' information and communications technology (ICT) skills (Samaniego Erazo et al. 2015; Del Blanco et al. 2010). Arising from early pioneers such as Baltra (Baltra 1990), the use of digital video games may offer an effective method to deliver SCL techniques through the connections between DGBL principles such as player identity and SCL tenets such as deep learning and understanding inside and outside the classroom (Gee 2005; Lea et al. 2003).

In his work on DGBL, Gee establishes that good games, by their very nature, deliver highquality learning, teaching players through gameplay the skills they need to complete the game, although not necessarily traditional educational content (Gee 2003). His works, alongside those of other researchers, identify that high-quality games are able to use a variety of techniques, such as building cycles of expertise and sandbox learning, to teach players the knowledge and skills they require in order to succeed at and eventually complete the game (Gee 2005; Hamari et al. 2016). Gee goes on to suggest that good-quality digital video games deliver a high-quality learning experience, thereby maximising the quality of learning outcomes (Gee 2005).

Many attempts have been made to harness the learning potential of games to deliver educational content in areas such as Mathematics and Language and Sciences (Abdul Jabbar and Felicia 2015). However, as with traditional teaching techniques, there is a need for a pedagogical underpinning upon which to base the design and utilisation of educational games (Tang et al. 2009). The use of SCL, as an effective group of teaching techniques, provides one such potential underpinning that has become increasingly a part of the delivery of teaching and learning within institutions (Krahenbuhl 2016). SCL has been shown to benefit student motivation (Nichols and Miller 1994; Urdan and Schoenfelder 2006), independence (The 
Scottish Government 2009; Motschnig-Pitrik and Holzinger 2002; Bonk and Cunningham 1998; Clements and Battista 1990), responsibility (Corno 1992) and flexibility (Gabel and Bunce 1994; Ward-Penny 2010; Taber 2009). The use of SCL to provide this pedagogical underpinning to DGBL, comprising SCDGBL, could therefore facilitate effective delivery of educational content through the medium of digital video games.

As with many services, the education sector faces increasing pressure to perform at an everhigher level. Increasing student numbers at university and global competition encourages the delivery of higher-trained, more well-equipped students (Marginson 2006). Meanwhile, societal pressures push teaching towards a more holistic education, and no longer is it acceptable to simply teach students to pass an exam. Alongside this are increasing calls for an ever higher degree of ICT literacy in students (Samaniego Erazo et al. 2015), needed to participate and compete in the workplace. SCDGBL could provide an important vehicle to address this, and reviews have been conducted on SCL (Rocca 2010; Din and Wheatley 2007) and DGBL (Abdul Jabbar and Felicia 2015) as separate entities. However, it is difficult to assess how well existing digital game-based learning delivers key tenets of SCL due to the absence of reviews covering SCDGBL as an entity in its own right. Subsequently, a state-of-the-art review on this would be timely and valuable to the SCDGBL research domain.

The remainder of this paper is organised as follows: in "Background: key concepts of student-centred digital game-based learning", the role of games as a vehicle for SCL will be explored, and the key concepts of DGBL and SCL broken down for presentation and conceptually linked, providing a starting point for thematic template analysis within the literature review. In "Determining the state of the art within student-centred digital gamebased learning literature", the literature identification, retrieval and thematic analysis process leading to the development of the conceptual framework is detailed. "Conceptual framework for student-centred digital game-based learning" follows on from this, wherein the conceptual framework is presented as developed from identified themes and scaffolded by the key concepts of SCDGBL. Conceptual frameworks aim to structure a presentation, in this case papers from a literature search, based upon a set of broad ideas and principles taken from relevant fields of enquiry (Reichel and Ramey 1987). For this paper, the two relevant fields are SCL and DGBL, in order to frame papers that combine both fields with equal weighting to form SCDGBL. In "Results", the use of this framework to systematically organise and present findings from the literature review will identify more clearly both areas of strength, and areas where interventions or game design can be adapted to better integrate both fields and deliver more effective and engaging learning. "Insights and reflections" delivers insights and reflections on the state of the art in SCDGBL literature based upon the organisation of this literature undertaken in "Results", culminating in a series of recommendations for future work in the area of SCDGBL. "Conclusions" then provides a summary of the work done within the paper, findings and suggestions.

\section{Background: key concepts of student-centred digital game-based learning}

This section presents the concepts that make up student-centred digital game-based learning, exploring first digital game-based learning and the principles behind it. This is followed by an exploration of student-centred learning and the tenets and techniques within it, leading to a presentation of the links between student-centred and digital game-based learning. 


\section{Digital game-based learning}

In examining the use of digital video games in DGBL, Gee broke down his ideas on aspects of gaming that deliver effective learning into thirteen principles, encompassed by three areas: learner empowerment, problem solving and understanding (Gee 2003). These are described in Table 1.

With regards to learner empowerment, the first principle, co-design, relates to giving players the feeling that their choices are the primary driving force behind the experience they are having. Customisation is the principle of players being able to make decisions about the way in which they play the game. Player identity is established through embodying someone in a situation, thus the lessons from that situation become personally relevant. Manipulation represents taking actions that affect the world, offering opportunities to bring the player closer to the experiences the game is mirroring.

Within problem solving, the principle of ordered problems relates to the idea that people lose interest if faced with something too far beyond their ability to solve, through complexity or lack of understanding. Ideal problems for both players and learners are those that are just towards the limits of where they are comfortable, conceptualised as pleasantly frustrating. Cycles of expertise describes the cycle of a learner picking up a new skill, practising until the skill becomes second nature to them and then having a challenge that requires the skill to be adapted. Information provision represents the idea that information in games is often provided either just in time for the player to make use of it or on demand so the player can draw upon it at need. Fish tank learning is the principle used to allow experimentation with a concept or mechanic in games, without the stresses that may impact the visibility of this effect. Sandbox learning provides an area of the game for experimentation and learning, but where it is difficult for things to go very far wrong. The final principle is that of skills as strategies, which brings skill practice into the strategy of the game, such that a player or learner is able to feel they are gaining an edge and progressing through the game.

Lastly, understanding embodies two principles: systems thinking, which relates to fitting the skills and ideas the game conveys as meaningful elements of the game world, and meaning from experience, which considers that learning occurs best when filtered through the experiences a learner has had.

Table 1 Gee's thirteen design principles for digital game-based learning

\begin{tabular}{ll}
\hline & Principle \\
\hline Learner empowerment & Co-design \\
& Customisation \\
& Player identity \\
& Manipulation \\
Problem solving & Ordered problems \\
& Pleasantly frustrating \\
& Cycles of expertise \\
& Information provision \\
& Fish tank learning \\
& Sandbox learning \\
& Skills as strategies \\
Understanding & Systems thinking \\
& Meaning from experience \\
\hline
\end{tabular}


It can be clearly seen that the overarching areas of learner empowerment, problem solving and understanding have a strong link to SCL as based on the consensus definition (Attard et al. 2010) given above. However, the aim of this paper is to evaluate SCDGBL literature, through giving both concepts equal weighting. In order to organise concepts relating to SCL and map their connections to DGBL, it is important to break down the broad consensus definition (Attard et al. 2010), which contains multiple facets and methods of delivery, into key elements.

\section{Student-centred learning}

Lea et al. (Lea et al. 2003) identified seven key tenets of SCL that comprehensively represent the student-centred experience:

1) Active learning - active learning utilises techniques that involve learners engaging and interacting with material on a level beyond simply cognitive processing.

2) Deep learning and understanding - the concept of deep learning and understanding offers opportunities for students to better internalise learning and connect it to concepts, characters and experiences, rather than isolating a learning experience from its context and presenting it for its own sake.

3) Increased responsibility and accountability - student responsibility is inherently linked to student independence: A responsible student may be described as one who understands and accepts their role as an independent learner (Corno 1992), thereby becoming accountable within this role. Such students may be more able to engage in an active learning partnership with the teacher, as both then understand the goals of the learning and are able to seek ways to achieve those goals (Corno 1992).

4) Sense of autonomy - student independence and autonomy are two major goals of the constructivist philosophy SCL which is derived from (Clements and Battista 1990). An independent student has the ability to seek out further knowledge and develop their skills on their own. Providing students with a sense of autonomy shifts the roles of teachers and lecturers towards facilitating the activity of the learner (Motschnig-Pitrik and Holzinger 2002; Bonk and Cunningham 1998).

5) Teacher and learner interdependence - a teacher may provide a human face to the learning that occurs in a classroom, being someone students can seek assistance from and who can answer questions or solve problems, and student-centred strategies can draw from this strength.

6) Mutual respect - the respect built allows students to learn from each other, and helps a teacher gain an accurate understanding of their student's ability while encouraging students to seek help and assistance, or share success, where appropriate.

7) Reflexive approach to teaching and learning - teachers and learners look back over work undertaken with a view to the efficiency of that learning and the reasons behind it. It enables the student to consider the processes behind their own best learning experiences, in order to answer the question "How do I learn?", and teachers to iterate upon these processes in response to the student's needs.

The above elements of SCL provide a suitable structure for conceptual linkage into areas of videogame design as explored by Gee (Table 1). Table 2 provides the linkage between these principles and the tenets of SCL defined by Lea et al. (Lea et al. 2003), along with the rationale for such linkage. An important consideration alongside this table is that the 
Table 2 Links between digital game-based learning principles and student-centred learning tenets

\begin{tabular}{|c|c|c|}
\hline Principle & SCL relationships & Rationale for linkage \\
\hline Co-design & $\begin{array}{l}\text {-Sense of autonomy } \\
\text {-Active learning }\end{array}$ & $\begin{array}{l}\text { This principle requires students to have a degree of autonomy } \\
\text { necessary to make the choices that drive their in-game experi- } \\
\text { ence. Decision-making and the implementation of decisions } \\
\text { within the game world are by nature active processes. }\end{array}$ \\
\hline Customisation & $\begin{array}{l}\text {-Sense of autonomy } \\
\text {-Reflexive approach to } \\
\text { teaching and learning }\end{array}$ & $\begin{array}{l}\text { That a player may make decisions about the way they play the } \\
\text { game necessitates the player having the autonomy to make } \\
\text { those decisions. A student making such decisions is } \\
\text { encouraged to reflect upon these decision points, with a view to } \\
\text { improving their gameplay and the learning obtained through it. }\end{array}$ \\
\hline Player identity & $\begin{array}{l}\text {-Deep learning and } \\
\text { understanding }\end{array}$ & $\begin{array}{l}\text { Through taking on a role within the game, a player's interactions } \\
\text { and experiences become less distant and more personal. } \\
\text { Learning gained through these interactions may feel more } \\
\text { practical and experiential. }\end{array}$ \\
\hline Manipulation & $\begin{array}{l}\text {-Active learning } \\
\text {-Deep learning and } \\
\text { understanding }\end{array}$ & $\begin{array}{l}\text { Learning through actions taken speaks to the core concept of } \\
\text { active learning. The information gained from such actions } \\
\text { becomes less something the student was told and more } \\
\text { something they have discovered, and are given the opportunity } \\
\text { to internalise themselves. }\end{array}$ \\
\hline $\begin{array}{l}\text { Ordered } \\
\text { problems }\end{array}$ & Sense of autonomy & $\begin{array}{l}\text { Effective implementation of ordered problems allows the student } \\
\text { to hone their skills, including knowledge and understanding as } \\
\text { they practise and progress at their own pace. This individual } \\
\text { progression indirectly provides learners a sense of control. }\end{array}$ \\
\hline $\begin{array}{l}\text { Pleasantly } \\
\text { frustrating }\end{array}$ & $\begin{array}{l}\text {-Sense of autonomy } \\
\text {-Increased responsibility } \\
\text { and accountability }\end{array}$ & $\begin{array}{l}\text { Surmounting an objective at the limit of a student's skill-based } \\
\text { comfort zone provides a student a recognition of this personal } \\
\text { achievement, which promotes autonomy. Such a well-placed } \\
\text { objective makes a student aware they are capable of achieving } \\
\text { it should they stretch their skills, inherently placing the re- } \\
\text { sponsibility to do so upon that student. }\end{array}$ \\
\hline $\begin{array}{l}\text { Cycles of } \\
\text { expertise }\end{array}$ & $\begin{array}{l}\text {-Reflexive approach to } \\
\text { teaching and learning }\end{array}$ & $\begin{array}{l}\text { In adapting to a new challenge, the student is prompted to reflect } \\
\text { upon the skill they have learned and consider ways in which it } \\
\text { may be adapted. When encountering a new skill, the student is } \\
\text { then aware that the skill will be expanded upon and is } \\
\text { encouraged to consider how best to approach it. }\end{array}$ \\
\hline $\begin{array}{l}\text { Information } \\
\text { provision }\end{array}$ & $\begin{array}{l}\text {-Sense of autonomy } \\
\text {-Teacher and learner } \\
\text { interdependence } \\
\text {-Reflexive approach to } \\
\text { teaching and learning }\end{array}$ & $\begin{array}{l}\text { Having information provided as students are about to or wish to } \\
\text { use it allows them to implement it without seeking further } \\
\text { explanation, thereby appearing to students as if they have } \\
\text { solved the problem without help. Bringing teachers into the } \\
\text { game world may allow teachers to take an active part in a } \\
\text { student's activities on a similar level, without breaking student } \\
\text { immersion. The ability to look back upon information gained } \\
\text { and use that as revision tool and a tool by which to gauge } \\
\text { progress fosters reflection. }\end{array}$ \\
\hline $\begin{array}{l}\text { Fish tank } \\
\quad \text { learning }\end{array}$ & -Active learning & $\begin{array}{l}\text { The experimentation with concepts and mechanics is a clear } \\
\text { implementation of active learning. }\end{array}$ \\
\hline $\begin{array}{l}\text { Sandbox } \\
\text { learning }\end{array}$ & $\begin{array}{l}\text {-Increased responsibility } \\
\text { and accountability }\end{array}$ & $\begin{array}{l}\text { Within a sandbox, the responsibility to experiment and learn falls } \\
\text { upon the student; in these areas, students receive little or no } \\
\text { prompting and are able to adopt an exploratory role and set } \\
\text { challenges or discover boundaries for themselves. }\end{array}$ \\
\hline $\begin{array}{l}\text { Skills as } \\
\text { strategies }\end{array}$ & $\begin{array}{l}\text {-Active learning } \\
\text {-Deep learning and } \\
\text { understanding } \\
\text { Sense of autonomy }\end{array}$ & $\begin{array}{l}\text { Practising skills and implementing strategies require the student to } \\
\text { take an active role. That the learning forms a part of the strategy } \\
\text { and progression of the game means the student is internalising } \\
\text { this towards an immediate purpose, rather than learning for its } \\
\text { own sake. The student individually coming up with a strategy } \\
\text { based upon their learning engenders a sense of personal control. }\end{array}$ \\
\hline $\begin{array}{l}\text { Systems } \\
\text { thinking }\end{array}$ & $\begin{array}{l}\text {-Deep learning \& } \\
\text { understanding }\end{array}$ & $\begin{array}{l}\text { The skills and ideas being meaningful elements of the game world } \\
\text { give them deeper meaning to the student than surface-level }\end{array}$ \\
\hline
\end{tabular}


Table 2 (continued)

\begin{tabular}{lll}
\hline Principle & SCL relationships & Rationale for linkage \\
\hline & -Active learning & (problem-based \\
learning) & $\begin{array}{l}\text { facts. For the skills and ideas to be meaningful elements that } \\
\text { are learned implies strongly that the challenges a student faces } \\
\text { requires the application of these skills. }\end{array}$ \\
$\begin{array}{c}\text { Meaning from } \\
\text { experience }\end{array}$ & $\begin{array}{c}\text {-Deep learning and } \\
\text { understanding } \\
\text {-Increased responsibility } \\
\text { and accountability }\end{array}$ & $\begin{array}{l}\text { of deep learning and understanding. The personal nature of the } \\
\text { experience gained gives students a level of accountability for } \\
\text { the choices made within that experience. This accountability } \\
\text { prompts students to consider how they may have made } \\
\text {-Sense of autonomy }\end{array}$ \\
& $\begin{array}{l}\text { alternative choices, promoting a sense of autonomy. } \\
\end{array}$
\end{tabular}

tenet of active learning in particular has received further research attention since Lea et al.'s work (Lea et al. 2003). As such, this area merits additional focus to ensure adequate exploration within this review.

\section{Concepts within the active learning tenet of student-centred learning}

Later work on the concept of active learning has broken this tenet down further, highlighting a number of nested techniques that deliver the concept; techniques include problem-based learning and peer-assisted learning approaches such as peer tutoring, collaborative learning and cooperative learning, which are briefly defined and their benefits stated in Table 3 .

The interlocking and nested nature of these techniques is demonstrated in Fig. 1 (Bishop and Verleger 2013); for example, problem-based learning is frequently achieved through group work utilising peer-assisted learning approaches (Bishop and Verleger 2013). In Fig. 1, cooperative learning is nested within collaborative learning as a more structured approach with defined roles (Bishop and Verleger 2013), although still distinct in identity (Bruffee 1995).

Having presented the key tenets of SCL and conceptually linked them with the design principles for DGBL, this formulates the lens through which to assess the literature in the area of SCDGBL. The strategy and analysis for this literature review will now be presented, leading to the conceptual framework developed from the thematic analysis.

\section{Determining the state of the art within student-centred digital game-based learning literature}

This section covers the exploration and literature collection process used to identify and analyse the state of the art in SCDGBL literature, from which to develop the framework. The search terms and inclusion criteria are presented, followed by an explanation of the analysis process.

\section{Identification of papers}

A systematic literature search was carried out in the area of digital game-based learning and student-centred learning. The paper selection process for this literature search is presented in Fig. 2. 
Table 3 Definitions and benefits of active learning techniques

\begin{tabular}{|c|c|c|}
\hline $\begin{array}{l}\text { Active learning } \\
\text { technique }\end{array}$ & Definition & Student benefits \\
\hline $\begin{array}{c}\text { Problem-based } \\
\text { learning }\end{array}$ & $\begin{array}{l}\text { Providing a problem or challenge to the } \\
\text { learner that becomes the stimulus for them } \\
\text { to learn or implement new skills. New } \\
\text { information is gathered through an element } \\
\text { of self-directed learning while the role of } \\
\text { the teacher is that of a facilitator or guide } \\
\text { (Barrows 1996). }\end{array}$ & $\begin{array}{l}\text { Motivation: giving students a reason to } \\
\text { complete work as they relate the problem } \\
\text { and solution to a real world context (Ames } \\
\text { 1992; Sungur and Tekkaya 2006) (Wijnia } \\
\text { et al. 2011) } \\
\text { Responsibility: allowing students to } \\
\text { understand what could go wrong in a real } \\
\text { situation if done incorrectly } \\
\text { Independence and flexibility: allowing } \\
\text { students enough space to find their own } \\
\text { way to an answer. }\end{array}$ \\
\hline $\begin{array}{c}\text { Peer-assisted } \\
\text { learning }\end{array}$ & $\begin{array}{l}\text { An umbrella term for all learning involving } \\
\text { peers. It represents a base level of learning } \\
\text { in which participants of similar status } \\
\text { (identifying as learners rather than teachers, } \\
\text { albeit different levels or ages) help and } \\
\text { support one another in their learning. This } \\
\text { encompasses peer tutoring, collaborative } \\
\text { learning and cooperative learning. }\end{array}$ & $\begin{array}{l}\text { Flexibility: Students learn to deal with each } \\
\text { other in a work capacity } \\
\text { Independence: Students learn their personal } \\
\text { strengths and how they can contribute. }\end{array}$ \\
\hline Peer tutoring & $\begin{array}{l}\text { Students work in pairs or groups, with one } \\
\text { (often older) student taking on an element } \\
\text { of a teaching role to explain concepts or } \\
\text { demonstrate techniques to the more } \\
\text { inexperienced students within the group. It } \\
\text { is in place as an educational technique in a } \\
\text { large number of institutions worldwide with } \\
\text { strong results (Topping 1996) }\end{array}$ & $\begin{array}{l}\text { Responsibility: Tutoring students appreciate } \\
\text { the role they have to the learners } \\
\text { Flexibility: Students come to appreciate } \\
\text { different ways of teaching and learning }\end{array}$ \\
\hline $\begin{array}{c}\text { Collaborative } \\
\text { learning }\end{array}$ & $\begin{array}{l}\text { Makes use of individual accountability within } \\
\text { a group situation to promote } \\
\text { interdependence within the group (Doolittle } \\
\text { 1995). Implementations may seek to pro- } \\
\text { mote group and self-evaluation through } \\
\text { social discourse with a goal of allowing } \\
\text { students to understand their areas of } \\
\text { strength and weakness by examining the } \\
\text { world, including themselves, from the per- } \\
\text { spective of others (Seel 2011). }\end{array}$ & $\begin{array}{l}\text { Responsibility: Students take a role within a } \\
\text { group and have peers relying on them to } \\
\text { complete work. Students learn to } \\
\text { self-evaluate from different perspectives. } \\
\text { Flexibility: Students come to appreciate } \\
\text { different ways of teaching and learning } \\
\text { Motivation: Peer expectations push students } \\
\text { forwards. }\end{array}$ \\
\hline $\begin{array}{c}\text { Cooperative } \\
\text { learning }\end{array}$ & $\begin{array}{l}\text { Seeks to develop further a student's } \\
\text { help-seeking behaviour, inviting students to } \\
\text { consider who or where they may get help } \\
\text { from and if there is help they may offer } \\
\text { (Bruffee 1995); it may be promoted through } \\
\text { methods such as enforced group roles to } \\
\text { encourage students to reach out to others } \\
\text { when at the limits of the area their role } \\
\text { includes (Bishop and Verleger 2013). }\end{array}$ & $\begin{array}{l}\text { Responsibility: Students take on the role of } \\
\text { identifying where and how to ask for } \\
\text { assistance and have peers relying on them } \\
\text { to complete work. } \\
\text { Independence: Students seek ways to get and } \\
\text { offer help. }\end{array}$ \\
\hline
\end{tabular}

The following databases were searched: Web of Science, JSTOR, EBSCOhost, SAGE, Teacher Reference Service, Taylor \& Francis, IEEE Xplore, ACM Digital Library and ScienceDirect. The list of databases was drawn up through an examination of previous literature reviews within this and related fields to locate the databases deemed relevant to those aspects and an examination of popular published papers to identify key journals where 


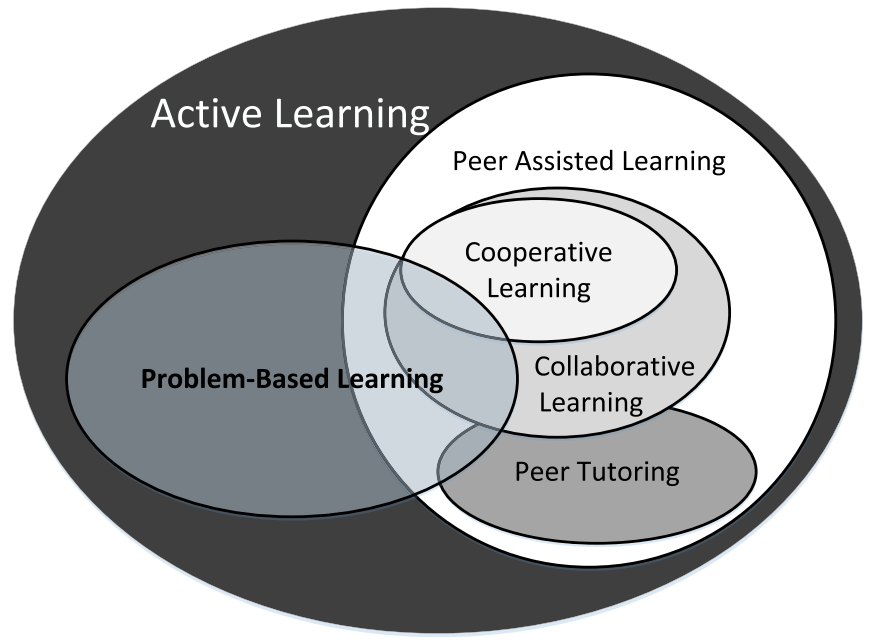

Fig. 1 Relationships between SCL theories and methods, adapted from Bishop and Verleger (Bishop and Verleger 2013)

databases were sought that included those publications. The database list includes databases that focus on both the technical and computing aspects, such as IEEE Xplore, and those that focused on the education and social science aspects, to ensure both approaches to this interdisciplinary field were taken into account.

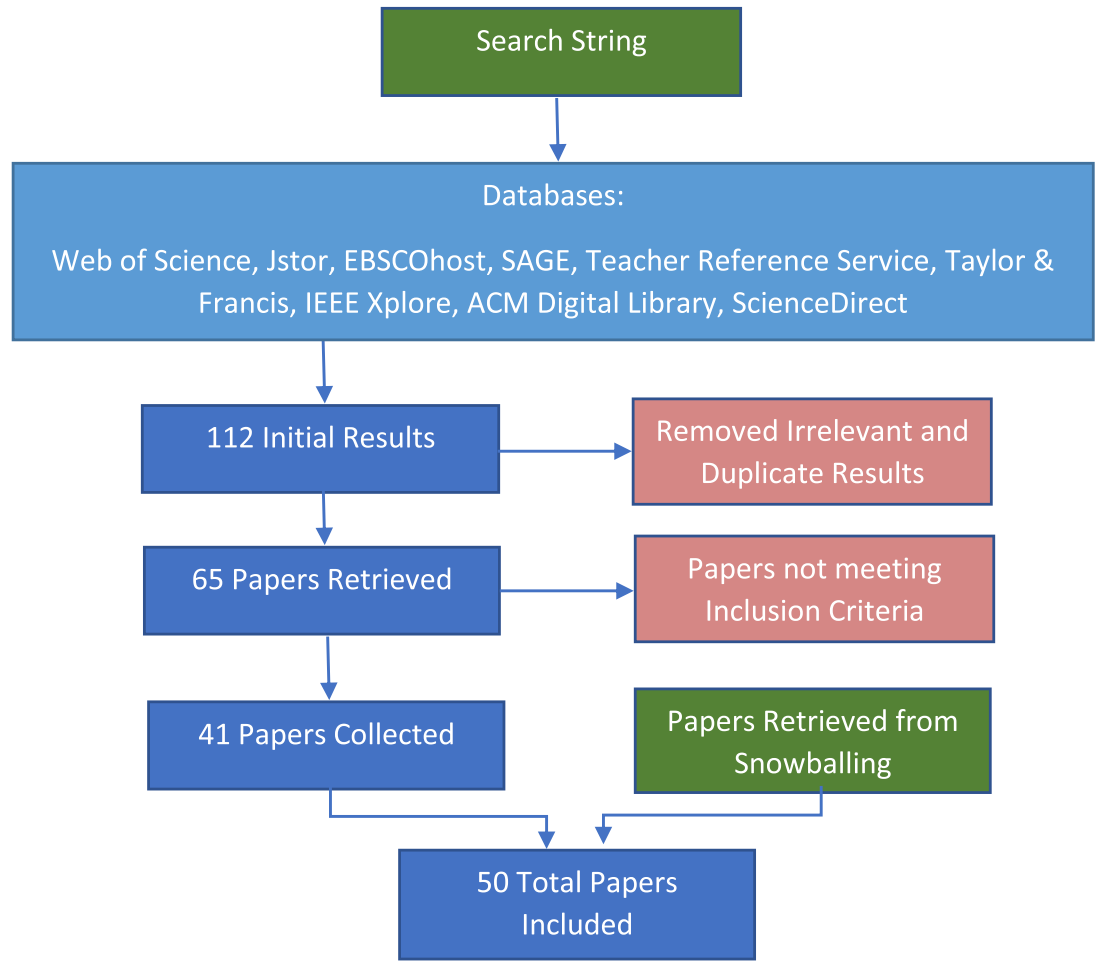

Fig. 2 Paper selection process 


\section{Development of a search string}

While the term digital game-based learning has achieved some recognition in recent years, it is far from being a ubiquitous term within the field. In particular, given the pace of research within education, a number of relevant papers were written before this term came to prominence and to exclude these papers through key wording was felt not to do justice to the state of research within the field. For this reason, a number of key phrases and words believed to be representative of digital game-based learning were used in order to draw out the scope of the literature. Results were limited to those that made some mention of a student-centred approach to avoid comparing papers seeking wildly differing things, such as those that may be based on alternative educational theories and that may look for a different definition of success.

With these factors in mind, the search string applied was as follows:

("game based" OR "game-based") AND ("student centered" OR "student-centered") AND ("computer game" OR "video game" OR "online game")

The abstracts of papers located were examined, and those that were found to be obviously unrelated were discarded. The remaining papers were then downloaded and examined. Papers that dealt with non-digital interventions were excluded following this examination; similarly, previous literature reviews were removed from the pool of papers to be categorised but retained for further information. Finally, a snowballing process was undertaken to find further papers referenced or referencing those located, that met the inclusion criteria.

\section{Inclusion criteria}

Papers included within the final literature sample met a number of criteria:

The paper must reference or demonstrate the utilisation of SCL concepts. The focus of this review on SCL as a pedagogical grounding for DGBL mandated an exploration of such within the papers addressed.

The paper must be based around or include game-based learning, and the games addressed must be digital in nature. While a variety of different games on different platforms were considered, it was felt inappropriate to use or compare non-digital games. The paper must have been published since 2007. Within the last 10 years, significant changes to both the education and computing fields have occurred, and it was felt that the current landscape, in terms of technology available within a modern-day school, made comparisons before this date of rapidly less relevance to games used today.

\section{Analysis strategy}

Following the identification of a dataset above, a thematic analysis was carried out to draw out the common themes arising within the papers. This technique involves the categorisation of common ideas and discussion points within papers to identify and categorise areas of similarity (Crabtree and Miller 1992). Papers were analysed, and sections relating to a particular topic were given a code.

Themes were derived based upon the codes using a hybrid approach of both inductive and deductive analysis. This approach provides an initial framework for the coding process while allowing for the development of themes through an iterative process while reflecting upon the 
identified common elements (Fereday and Muir-Cochrane 2006). The initial themes were drawn from the design principles of DGBL (Gee 2003) and the tenets of SCL (Lea et al. 2003), allowing both techniques in game design and in teaching to be considered with equal weighting, and categorised under one or more of these deductive themes. This hybrid approach allows exploration of the extent to which current SCDGBL literature delivers on the tenets of SCL and the DGBL principles by which this delivery is achieved, while also allowing consideration of other common game design and educational themes as inductively derived from the literature crossing both fields.

The codes were examined and links between them identified, assisted by the conceptual linkage between DGBL and SCL as formulated in Table 3. These links allowed the transition from codes identifying a certain aspect, to themes exploring a similar idea within the literature. Some codes were applied directly into the pre-existing themes, while in other cases, new themes were created on an inductive basis. Through an iterative process, codes were transitioned into themes directly, or combined as subthemes within a larger theme. During this period, both deductive and emerging themes were considered in the broader viewpoints of student-centred learning and game-based learning to tie them to existing literature where appropriate.

The results of this were considered alongside existing literature reviews on related areas and the conceptual framework presented below drawn up from the results. This framework organises and displays the student-centred digital game-based learning landscape as it currently exists, represented by the current literature in the field. The conceptual framework will now be presented, along with an explanation of how it was derived from the thematic analysis.

\section{Conceptual framework for student-centred digital game-based learning}

The overall structure of the framework is presented in Fig. 3, with further detail explained below.

Firstly, SCDGBL interventions described in the literature can be stratified using the conceptual framework according to the player engagement, intervention type and game design categories. These categories represent common themes inductively derived from the SCDGBL literature review.

Number of players was a strong emerging theme, additionally important due to the strong role of peer-assisted learning within SCL. Study setting such as education level (primary, 411 years, secondary, 11-18 years, tertiary, 19+ years) was prominent within the literature due to foreseeable impacts on game content and complexity. Similarly, setting inside/outside the classroom required consideration for practical application/deployment of interventions (Kern and Carpenter 1986). Study type was incorporated to assess validity and generalisability. Aspects of game design not covered by Gee that emerged as themes included platform, for practical application/deployment and the use of emerging technologies such as virtual or augmented reality, and development style, noting that education-led developments were likely to have differing goals vs commercial-led.

These additional layers of stratification for SCDGBL interventions feed directly into the level of integration of both concepts, and therefore, the conceptual framework presents these first. The interventions can subsequently be evaluated according to the second part of the conceptual framework: educational factors, which encompass deductive themes informed by Gee's design principles for DGBL, and Lea et al.'s SCL tenets, while considering the key 


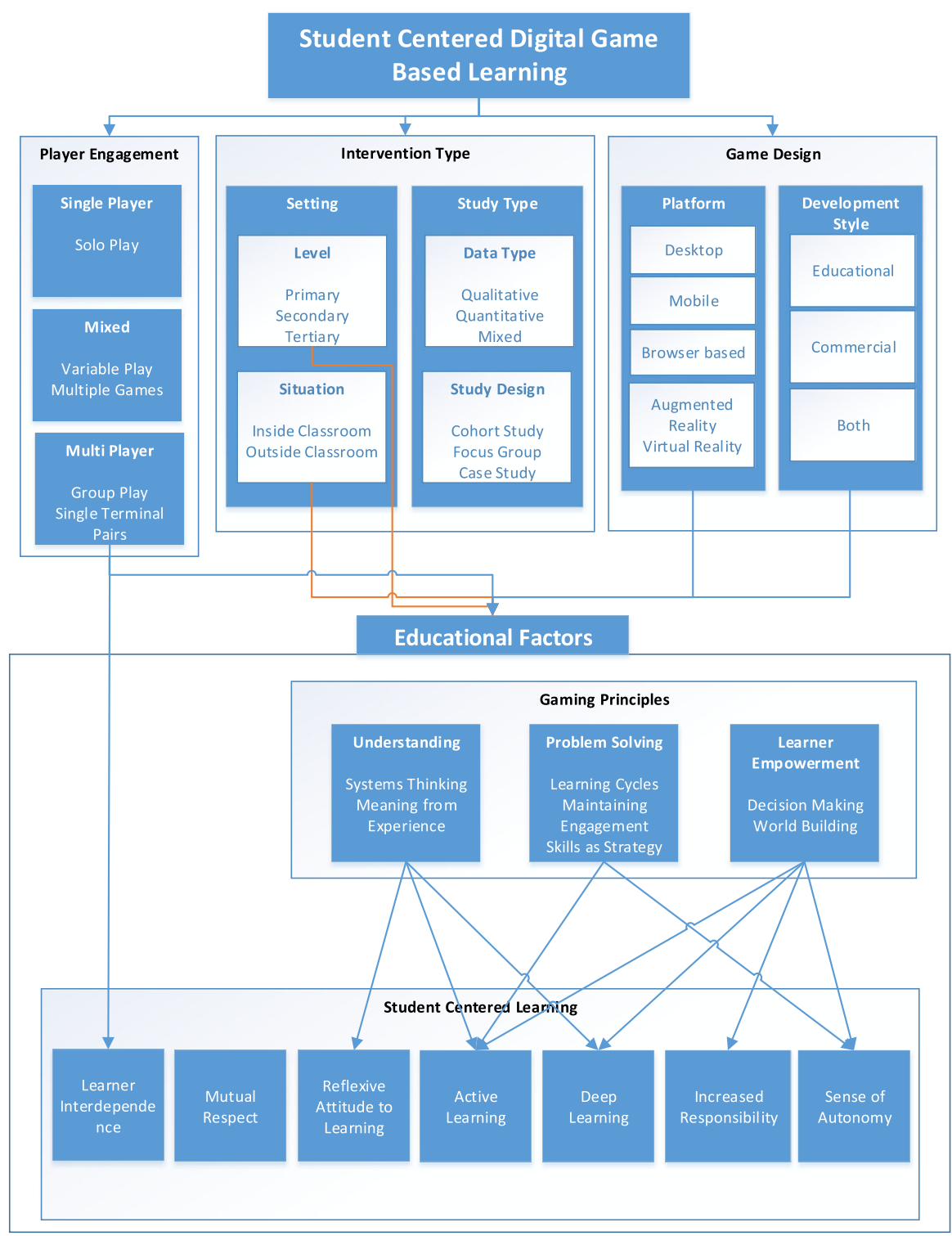

Fig. 3 Conceptual framework for student-centred digital game-based learning

relationships between the two concepts. Organising the literature by these inductive and deductive themes as presented within the conceptual framework enables consideration of the extent to which SCDGBL interventions deliver on these key components.

Some design principles for DGBL as explored by Gee have been re-categorised for easier display within the framework and resulting tables: Within the problem solving sub-category, learning cycles combines the principles of ordered problems and cycles of expertise, as both principles describe ways to encourage continued learning and game participation by providing students with cycles of learning. Maintaining engagement combines the principles of pleasant 
frustration, fish tank learning, information provision and sandbox learning. These are all intended to alleviate frustration in players/students to maintain long-term engagement, ensuring deeper learning. Within the learner empowerment sub-category, co-design and customisability are grouped under decision-making, as both relate to encouraging and allowing students to make decisions before and during the game. Player identity and manipulation were grouped together as world building, as they relate to ways players are made to feel closer and more involved with the game, and the deeper embedded learning to be gained from doing so.

Having presented the conceptual framework, it will now be used to systematically organise and present the findings from the literature review for subsequent synthesis and discussion.

\section{Results}

These papers were examined and categorised as explored in Fig. 3. Results are tabulated according to player engagement category, and then stratified within each table according to the first level of the game type (group), study type (data type) and setting (level) categories, denoted in italics. This enables easy recognition of qualitative, quantitative, mixed method and theoretical studies (separated by thicker borders), and then identification of relevant studies within primary, secondary and tertiary academic levels through shading (primary- and tertiarylevel studies are shaded). This demonstrates how the conceptual framework can be used to organise and present the literature for ease of evaluation.

\section{Single player}

Table 4 presents studies $(n=26)$ that discussed or utilised exclusively single player games with a student-centred learning basis. The remainder of this section explores the key characteristics of these studies.

\section{Game type}

This category includes a variety of different types of games, ranging from simulation for use in medical training (Monteiro et al. 2011) and collections of mini-games designed to teach a specific element (Garcia and Pacheco 2013) to exploration games where the player is offered a world to explore (Diah et al. 2012).

The majority of papers within this table dealt with educational games (E) (Baytak and Land 2011; Shafie and Ahmad 2010; So 2012; Bowen et al. 2014; Seng and Yatim 2014; Peng et al. 2017; Garcia and Pacheco 2013; Hwang et al. 2013; Hwang et al. 2015; Khamparia and Pandey 2018; Wang et al. 2018; Yang et al. 2010; Annetta et al. 2013; Liu and Chu 2010; Ameerbakhsh et al. 2018; Neville et al. 2009; Kiger et al. 2012; Su and Cheng 2013; ter Vrugte et al. 2017; Diah et al. 2012; Monteiro et al. 2011; Norton et al. 2008). Many appear to have been designed exclusively for the research study, e.g. "MathQuest" (Shafie and Ahmad 2010) which targeted 10-11-year-old students to provide mathematics education blended with an immersive role-playing experience. Others deployed pre-existing educational games, e.g. mobile learning applications (Kiger et al. 2012). However, some commercial games (C) were used to achieve research aims (Shahriarpour 2014; Lin and Lin 2014; Boutsika 2014), either adapted using packaged tools to better fit the needs of the classroom, or presented as is, e.g. use of SimCity (Lin and Lin 2014) to investigate which elements of the game were stimulating 


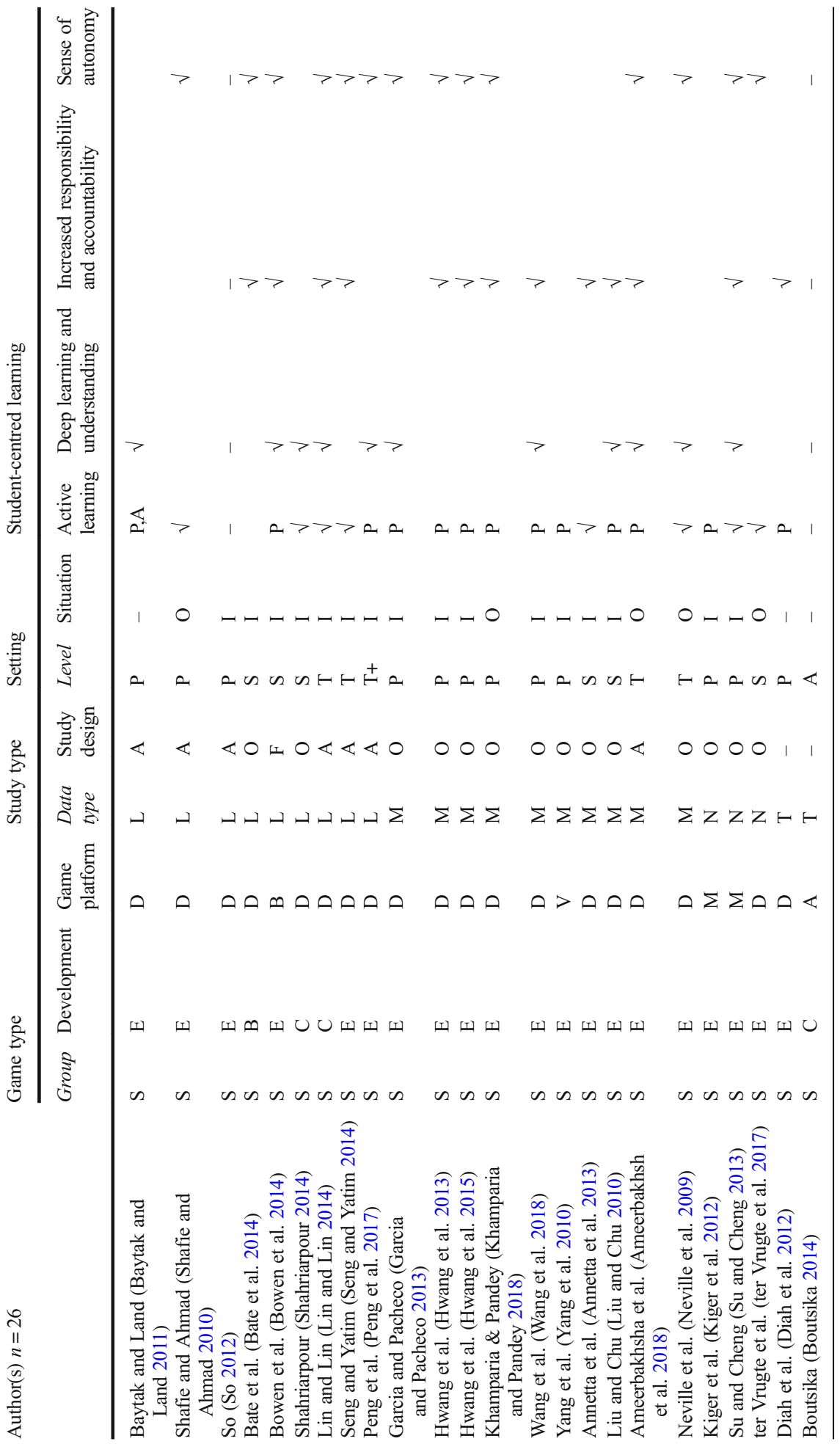




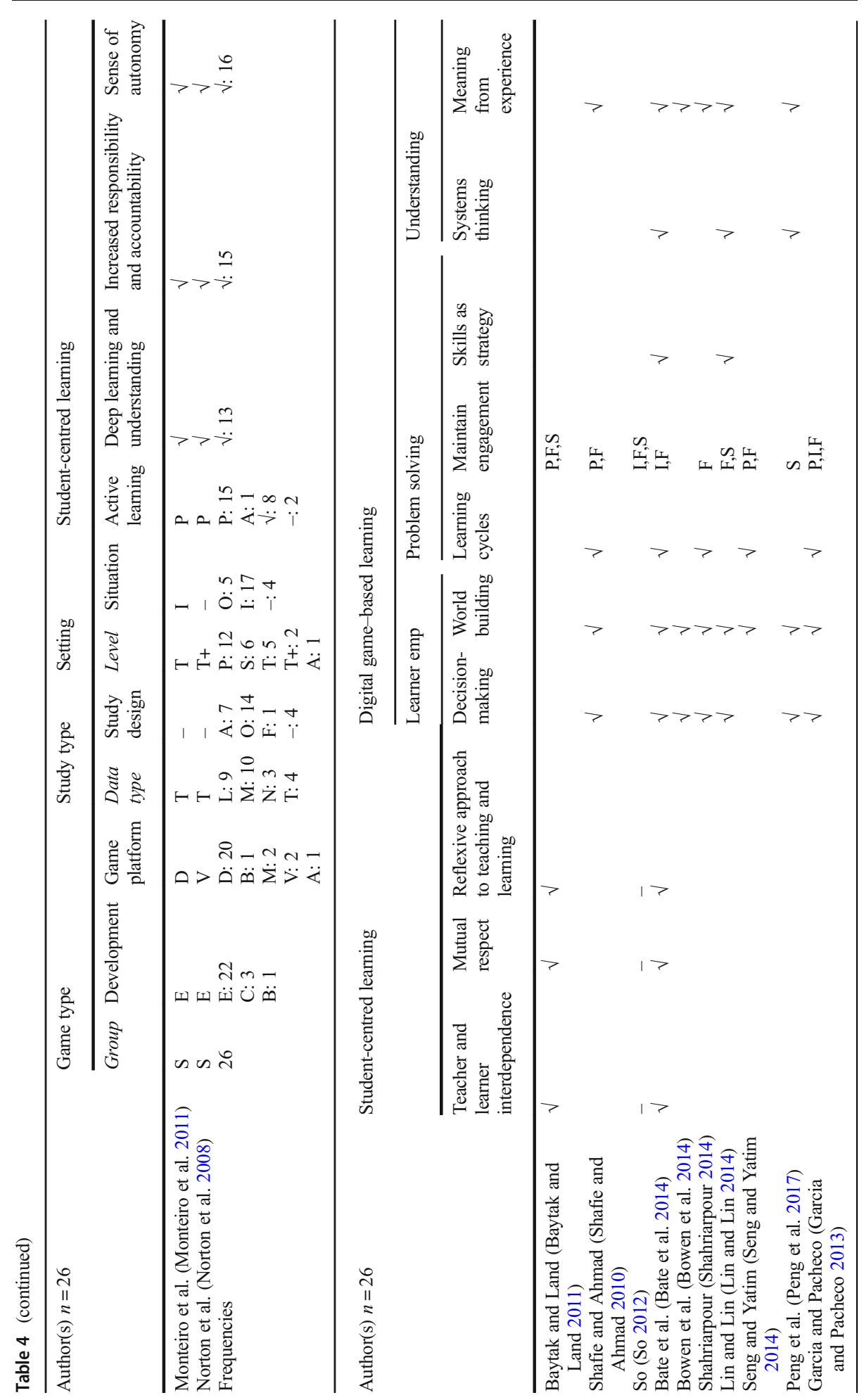




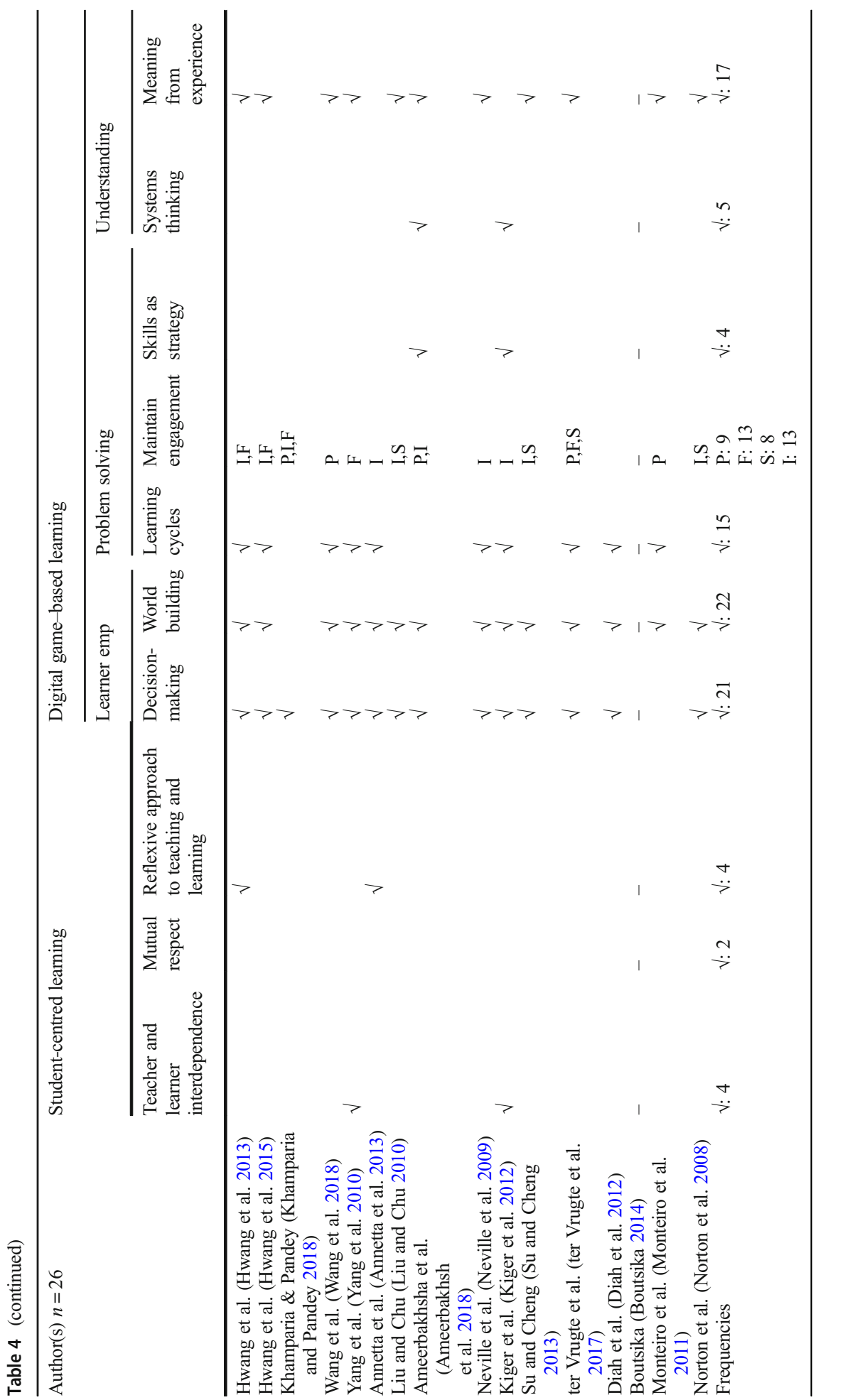


learning and understanding in university students. The remaining paper used both (B) educational and commercial games in discussion on the effect of increased gaming within classrooms and schools (Bate et al. 2014), focusing on the broader effect of accessible gaming in a school environment (Bate et al. 2014).

The majority of single-player games were desktop (D) games (Baytak and Land 2011; Shafie and Ahmad 2010; So 2012; Bate et al. 2014; Shahriarpour 2014; Lin and Lin 2014; Seng and Yatim 2014; Peng et al. 2017; Garcia and Pacheco 2013; Hwang et al. 2013; Hwang et al. 2015; Khamparia and Pandey 2018; Wang et al. 2018; Annetta et al. 2013; Liu and Chu 2010; Ameerbakhsh et al. 2018; Neville et al. 2009; ter Vrugte et al. 2017; Diah et al. 2012; Monteiro et al. 2011). Studies using these kinds of games include an investigation into the effect of embedding concept maps which utilised desktop systems with 11-year-old pupils (Hwang et al. 2013) and discussion on the development and deployment of a game to teach resuscitation as part of a university course (Monteiro et al. 2011). A single Browser-based (B) game, "Green Acres High" (Bowen et al. 2014), was separated out as it was possible to identify the game as such (Bowen et al. 2014). Mobile games (M) were also under-represented in the table (Kiger et al. 2012; Su and Cheng 2013), with one study making use of a wide selection of math-based applications available on Apple devices (Kiger et al. 2012). A small number of games were using emerging technologies such as augmented reality (A) (Boutsika 2014) and virtual reality (V) technology (Yang et al. 2010; Norton et al. 2008). These technologies may utilise desktop, console or mobile platforms in order deliver a different experience, e.g. utilising Microsoft's Kinect system to deliver interactive tailored learning to autism sufferers (Boutsika 2014). This includes educational simulations, e.g. replicating a chemical plant within an education environment for both undergraduate university students and plant staff (Norton et al. 2008).

\section{Study type}

Studies in this table collected primarily qualitative data (Baytak and Land 2011; Shafie and Ahmad 2010; So 2012; Bate et al. 2014; Bowen et al. 2014; Shahriarpour 2014; Lin and Lin 2014; Seng and Yatim 2014; Peng et al. 2017), such as interviews (Baytak and Land 2011) or survey free-text responses (Bate et al. 2014). Mixed methods were also well represented (Garcia and Pacheco 2013; Hwang et al. 2013; Hwang et al. 2015; Khamparia and Pandey 2018; Wang et al. 2018; Yang et al. 2010; Annetta et al. 2013; Liu and Chu 2010; Ameerbakhsh et al. 2018; Neville et al. 2009). A small number of studies (Kiger et al. 2012; Su and Cheng 2013) collected primarily quantitative data, e.g. class test data to analyse the intervention effects (Su and Cheng 2013) or questionnaire data (Kiger et al. 2012). The final category was a small number of purely theoretical papers (ter Vrugte et al. 2017; Diah et al. 2012; Boutsika 2014; Monteiro et al. 2011; Norton et al. 2008), where no intervention was performed; however, new ideas were proposed that may form a basis for future studies; e.g. one paper discussed creation of a recycling themed educational game, without data to demonstrate its effectiveness (Diah et al. 2012).

Cohort studies made up the largest group of study designs (Bate et al. 2014; Shahriarpour 2014; Garcia and Pacheco 2013; Hwang et al. 2013; Hwang et al. 2015; Khamparia and Pandey 2018; Wang et al. 2018; Yang et al. 2010; Annetta et al. 2013; Liu and Chu 2010; Neville et al. 2009; Kiger et al. 2012; ter Vrugte et al. 2017), with larger accompanying sample sizes (ranging from $n=120$ (Bate et al. 2014) to $n=15$ (Neville et al. 2009)). There were a smaller number of case studies (Baytak and Land 2011; Shafie and Ahmad 2010; So 2012; Lin 
and Lin 2014; Seng and Yatim 2014; Peng et al. 2017; Ameerbakhsh et al. 2018) where assessment was limited to primarily a small group of individuals (So 2012) or to a single class (Baytak and Land 2011). A single study employed a focus group design (Bowen et al. 2014).

\section{Setting}

Many papers addressed primary age (5-11) students (Baytak and Land 2011; Shafie and Ahmad 2010; So 2012; Garcia and Pacheco 2013; Hwang et al. 2013; Hwang et al. 2015; Khamparia and Pandey 2018; Wang et al. 2018; Yang et al. 2010; Kiger et al. 2012; Su and Cheng 2013; Diah et al. 2012); these included examples that may address the entire primary spectrum (So 2012) or targeting a particular year group, e.g. aged 10-11 (Hwang et al. 2013). Secondary (11-18) was well represented (Bate et al. 2014; Bowen et al. 2014; Shahriarpour 2014; Annetta et al. 2013; Liu and Chu 2010; ter Vrugte et al. 2017); however, only one paper attempted longitudinal study over a 3-year period (Bate et al. 2014), with most studies focusing on a particular class or group within an academic year. Tertiary age $(17+)$ was the focus of another group of papers (Lin and Lin 2014; Seng and Yatim 2014; Peng et al. 2017; Ameerbakhsh et al. 2018; Neville et al. 2009; Monteiro et al. 2011; Norton et al. 2008), one of which investigated adult learning alongside university students (Norton et al. 2008).

A majority of studies were undertaken inside the classroom, with attempts made to place the learning within a normal school context (So 2012; Bate et al. 2014; Bowen et al. 2014; Shahriarpour 2014; Lin and Lin 2014; Seng and Yatim 2014; Peng et al. 2017; Garcia and Pacheco 2013; Hwang et al. 2013; Hwang et al. 2015; Wang et al. 2018; Yang et al. 2010; Annetta et al. 2013; Liu and Chu 2010; Kiger et al. 2012; Su and Cheng 2013; Monteiro et al. 2011). Such studies typically looked to integrate classroom teachers and blend the intervention to preserve the normal school experience for participating students (Baytak and Land 2011; Hwang et al. 2013). A small number of studies (Shafie and Ahmad 2010; Khamparia and Pandey 2018; Ameerbakhsh et al. 2018; Neville et al. 2009; ter Vrugte et al. 2017) were undertaken that took learning outside the usual school environment, e.g. as a focus on student engagement with games at home (Neville et al. 2009), or interventions where students were removed from regular lessons to play the game (Shafie and Ahmad 2010).

\section{Student-centred learning}

Active learning was almost universally represented in the papers examined; only a few theoretical papers did not include some level of this. However, the delivery method for active learning was often not specified in many papers (Shafie and Ahmad 2010; Shahriarpour 2014; Lin and Lin 2014; Seng and Yatim 2014; Annetta et al. 2013; Neville et al. 2009; Su and Cheng 2013; ter Vrugte et al. 2017), or the game was used as a catalyst to inspire learning rather than as a more direct vehicle for learning itself (Lin and Lin 2014). A number of papers integrated elements of problem-based learning into interventions or discussions (Baytak and Land 2011; Bowen et al. 2014; Peng et al. 2017; Garcia and Pacheco 2013; Hwang et al. 2013; Hwang et al. 2015; Khamparia and Pandey 2018; Wang et al. 2018; Yang et al. 2010; Liu and Chu 2010; Ameerbakhsh et al. 2018; Kiger et al. 2012; Diah et al. 2012; Monteiro et al. 2011; Norton et al. 2008), e.g. a game designed around money problems such as when to spend or save created learning experiences off these problems (Hwang et al. 2013). Only one paper included peer-assisted learning elements, which, while using single-player games developed by students, integrated peer discussion through a group-based evaluation process 
students were able to take part in once the solo design and testing had been completed (Baytak and Land 2011).

Deep learning and understanding was well represented (Baytak and Land 2011; Bowen et al. 2014; Shahriarpour 2014; Lin and Lin 2014; Peng et al. 2017; Garcia and Pacheco 2013; Wang et al. 2018; Liu and Chu 2010; Ameerbakhsh et al. 2018; Neville et al. 2009; Su and Cheng 2013; Monteiro et al. 2011; Norton et al. 2008), e.g. carrying over the consequences between dependent game components to reinforce intended learning outcomes, thereby tying them closely to the student experience throughout the game (Peng et al. 2017). Increased responsibility and accountability was another well-represented category (Bate et al. 2014; Bowen et al. 2014; Lin and Lin 2014; Seng and Yatim 2014; Hwang et al. 2013; Hwang et al. 2015; Khamparia and Pandey 2018; Wang et al. 2018; Annetta et al. 2013; Liu and Chu 2010; Ameerbakhsh et al. 2018; Su and Cheng 2013; Diah et al. 2012; Monteiro et al. 2011; Norton et al. 2008), e.g. use of the freedom of a sandbox game such as SimCity provides while learning concepts, with even failure in conveying meaningful information and creating a discussion point (Lin and Lin 2014). Sense of autonomy was also addressed in a number of papers (Shafie and Ahmad 2010; Bate et al. 2014; Bowen et al. 2014; Lin and Lin 2014; Seng and Yatim 2014; Peng et al. 2017; Garcia and Pacheco 2013; Hwang et al. 2013; Hwang et al. 2015; Khamparia and Pandey 2018; Ameerbakhsh et al. 2018; Neville et al. 2009; Su and Cheng 2013; ter Vrugte et al. 2017; Monteiro et al. 2011; Norton et al. 2008), e.g. integrating faded worked examples into a game to give students needing help a feeling they have completed the work without teacher input, building confidence in their ability to work autonomously (ter Vrugte et al. 2017). Although some game genres such as text-based adventures could be perceived as potentially limiting decision-making, another paper demonstrated that providing a carefully selected breadth of responses and providing similarities between the players and their avatar can still give the sense that a student can choose very different paths (Bowen et al. 2014).

Teacher and learner interdependence (Baytak and Land 2011; Bate et al. 2014; Yang et al. 2010; Kiger et al. 2012), mutual respect (Baytak and Land 2011; Bate et al. 2014) and a reflexive approach to teaching and learning (Baytak and Land 2011; Bate et al. 2014; Hwang et al. 2013; Annetta et al. 2013) were least represented within single-player games; however, some examples did exist to evidence that these can be integrated into student-centred digital game-based learning interventions, e.g. Kiger et al.'s mobile learning intervention was closely integrated within a standard classroom situation to preserve the teacher-learner relationship (Kiger et al. 2012). Integration of student/ teacher involvement in the games design and testing process demonstrates a way to create and reinforce respect between peers and teachers as the games are evaluated and students may experience other creations (Baytak and Land 2011). Finally, Hwang et al. utilised cycles of learning where students not demonstrating an appropriate level of understanding are encouraged to seek out more information and return, engendering a reflexive approach (Hwang et al. 2015).

\section{Digital game-based learning principles}

Learner empowerment In terms of learner empowerment, the decision-making principle was evident in a majority of studies (Shafie and Ahmad 2010; Bate et al. 2014; Bowen et al. 2014; Shahriarpour 2014; Lin and Lin 2014; Peng et al. 2017; Garcia and Pacheco 2013; Hwang et al. 2013; Hwang et al. 2015; Khamparia and Pandey 2018; Wang et al. 2018; Yang et al. 
2010; Annetta et al. 2013; Liu and Chu 2010; Ameerbakhsh et al. 2018; Neville et al. 2009; Kiger et al. 2012; Su and Cheng 2013; ter Vrugte et al. 2017; Diah et al. 2012; Norton et al. 2008). This principle was integrated through, for example, adventure games (Shafie and Ahmad 2010) and visual novels, where such decisions are the main interaction players have (Bowen et al. 2014). World building was a well-represented section, appearing in a number of studies (Shafie and Ahmad 2010; Bate et al. 2014; Bowen et al. 2014; Shahriarpour 2014; Lin and Lin 2014; Seng and Yatim 2014; Peng et al. 2017; Garcia and Pacheco 2013; Hwang et al. 2013; Hwang et al. 2015; Wang et al. 2018; Yang et al. 2010; Annetta et al. 2013; Liu and Chu 2010; Ameerbakhsh et al. 2018; Neville et al. 2009; Kiger et al. 2012; Su and Cheng 2013; ter Vrugte et al. 2017; Diah et al. 2012; Monteiro et al. 2011; Norton et al. 2008). Commercial games such as SimCity allowed players to learn while creating and developing their world during their integration of the game into the classroom (Lin and Lin 2014). Hwang et al. (Hwang et al. 2015) made use of these principles in their social science-based game, allowing students the ability to interact with and manipulate objects and non-player characters in the world as a part of their learning process.

Problem solving Use of learning cycles was observed in a number of papers (Shafie and Ahmad 2010; Bate et al. 2014; Shahriarpour 2014; Seng and Yatim 2014; Garcia and Pacheco 2013; Hwang et al. 2013; Hwang et al. 2015; Wang et al. 2018; Yang et al. 2010; Annetta et al. 2013; Neville et al. 2009; Kiger et al. 2012; ter Vrugte et al. 2017; Diah et al. 2012; Monteiro et al. 2011), e.g. providing feedback on mistakes and encouraging players to repeat and improve with each iteration to master resuscitation techniques (Monteiro et al. 2011), or task-level progression to encourage understanding of one skill before progression to the next (Garcia and Pacheco 2013).

Multiple methods of maintaining engagement were often used within papers. A number of papers sought to make their games pleasantly frustrating (Baytak and Land 2011; Shafie and Ahmad 2010; Seng and Yatim 2014; Garcia and Pacheco 2013; Khamparia and Pandey 2018; Wang et al. 2018; Ameerbakhsh et al. 2018; ter Vrugte et al. 2017; Monteiro et al. 2011), e.g. multiple levels that increasingly stretch skill, with each new element becoming routine within the next level (Seng and Yatim 2014), and or utilised information provision (So 2012; Bate et al. 2014; Garcia and Pacheco 2013; Hwang et al. 2013; Hwang et al. 2015; Khamparia and Pandey 2018; Annetta et al. 2013; Liu and Chu 2010; Ameerbakhsh et al. 2018; Neville et al. 2009; Kiger et al. 2012; Su and Cheng 2013; Norton et al. 2008), e.g. prompts with commonly forgotten information and relevant instructions ( $\mathrm{Su}$ and Cheng 2013). Fish tank learning was featured in a number of games (Baytak and Land 2011; Shafie and Ahmad 2010; So 2012; Bate et al. 2014; Shahriarpour 2014; Lin and Lin 2014; Seng and Yatim 2014; Garcia and Pacheco 2013; Hwang et al. 2013; Hwang et al. 2015; Khamparia and Pandey 2018; Yang et al. 2010; ter Vrugte et al. 2017), e.g. allowing students to observe poor choices and then retake those decisions after seeing the outcome (Hwang et al. 2015). The final engagementbased principle is that of sandbox learning (Baytak and Land 2011; So 2012; Lin and Lin 2014; Peng et al. 2017; Liu and Chu 2010; Su and Cheng 2013; ter Vrugte et al. 2017; Norton et al. 2008), e.g. allowing players to explore the results of their actions and how that affects a simulated cityscape (Lin and Lin 2014).

Skills as strategy was the least well-represented category within problem solving (Bate et al. 2014; Lin and Lin 2014; Ameerbakhsh et al. 2018; Kiger et al. 2012), although some papers used games that were able to tie a student's progression to their understanding, with greater understanding of the game mechanics allowing greater success (Lin and Lin 2014). 
Understanding Systems thinking was found within a small number of studies (Bate et al. 2014; Lin and Lin 2014; Peng et al. 2017; Ameerbakhsh et al. 2018; Kiger et al. 2012), e.g. using simulation to develop an understanding of game concepts to progress clearly provides the real-world learning outcomes (Peng et al. 2017).

Meaning from experience was better represented (Shafie and Ahmad 2010; Bate et al. 2014; Bowen et al. 2014; Shahriarpour 2014; Lin and Lin 2014; Peng et al. 2017; Hwang et al. 2013; Hwang et al. 2015; Wang et al. 2018; Yang et al. 2010; Liu and Chu 2010; Ameerbakhsh et al. 2018; Neville et al. 2009; Su and Cheng 2013; ter Vrugte et al. 2017; Monteiro et al. 2011; Norton et al. 2008). This was particularly evident in commercial games utilised in language learning, where language skills developed as a natural part of the game are applicable in similar situations in life (Liu and Chu 2010; Neville et al. 2009).

\section{Reflective summary}

The single player category was dominated by educational games in desktop format, often designed exclusively for the study reported. Mobile and virtual or augmented reality platforms were rarely utilised. Studies were primarily qualitative or mixed methods, accompanied by a small number of theoretical papers - few collected quantitative data on educational outcomes. Cohort studies were favoured in this category over other study designs but mainly focused on in-classroom deployment within academic year groups/classes, with limited use of follow-up or longitudinal deployment of interventions. Year groups were often primary level, but implementation within secondary and tertiary levels was also demonstrated.

A cross section of SCL tenets was implemented within interventions discussed or deployed; however, the tenets were not represented in a balanced fashion within individual papers. Active learning and tenets speaking to the learner as an individual or involving internalisation were well represented (deep learning and understanding, increased responsibility and accountability, a sense of autonomy). However, the representation of other tenets was poor or only specified in a limited fashion, such as peerassisted forms of active learning, and tenets that incorporate interaction with peers or teachers, such as teacher and learner interdependence, mutual respect, or reflection on the part of both students and teachers, i.e. a reflexive approach to teaching and learning. In terms of design principles for DGBL, some principles were better represented than others. Learner empowerment principles such as decision-making and world building were evidenced in many studies as key delivery mechanisms for SCL tenets, along with problem solving approaches that employed learning cycles and multiple methods of maintaining engagement (although sandbox practise was relatively less featured). However, skills as strategy was a problem solving design principle with limited implementation, and systems thinking was rarely deployed as a design principle to facilitate understanding, with many papers ascribing to meaning from experience instead.

\section{Mixed and variable play}

Table 5 presents studies $(n=12)$ that used or discussed a combination of single and multiplayer games ( $n=7$ (King 2015; Kim and Yao 2010; Owston 2009; Ucus 2015; Kennedy-Clark 2011; Kebritchi 2008; Barr 2018)), and also includes studies where the number of players was varied or not specified, without a particular focus on the effects of 


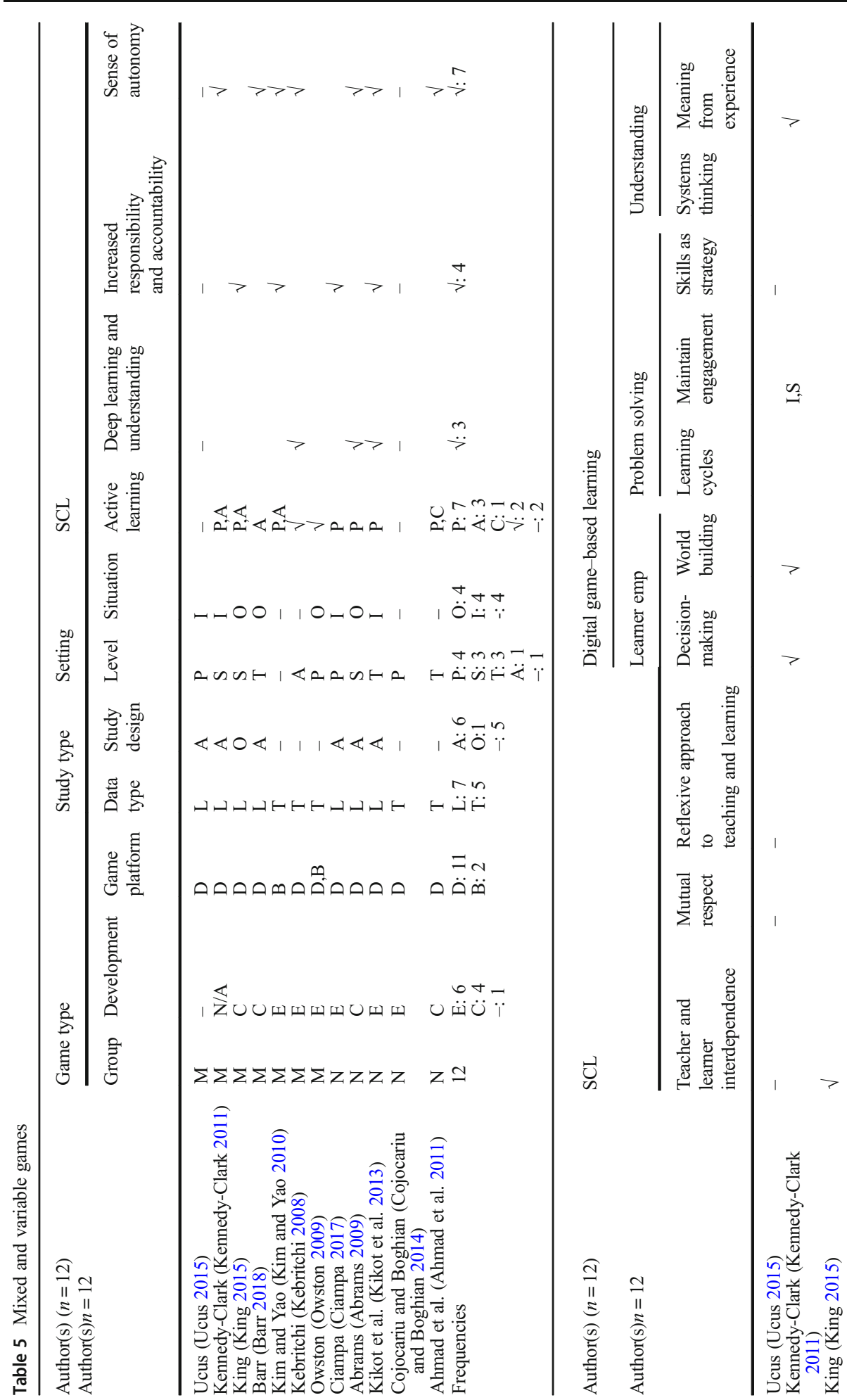




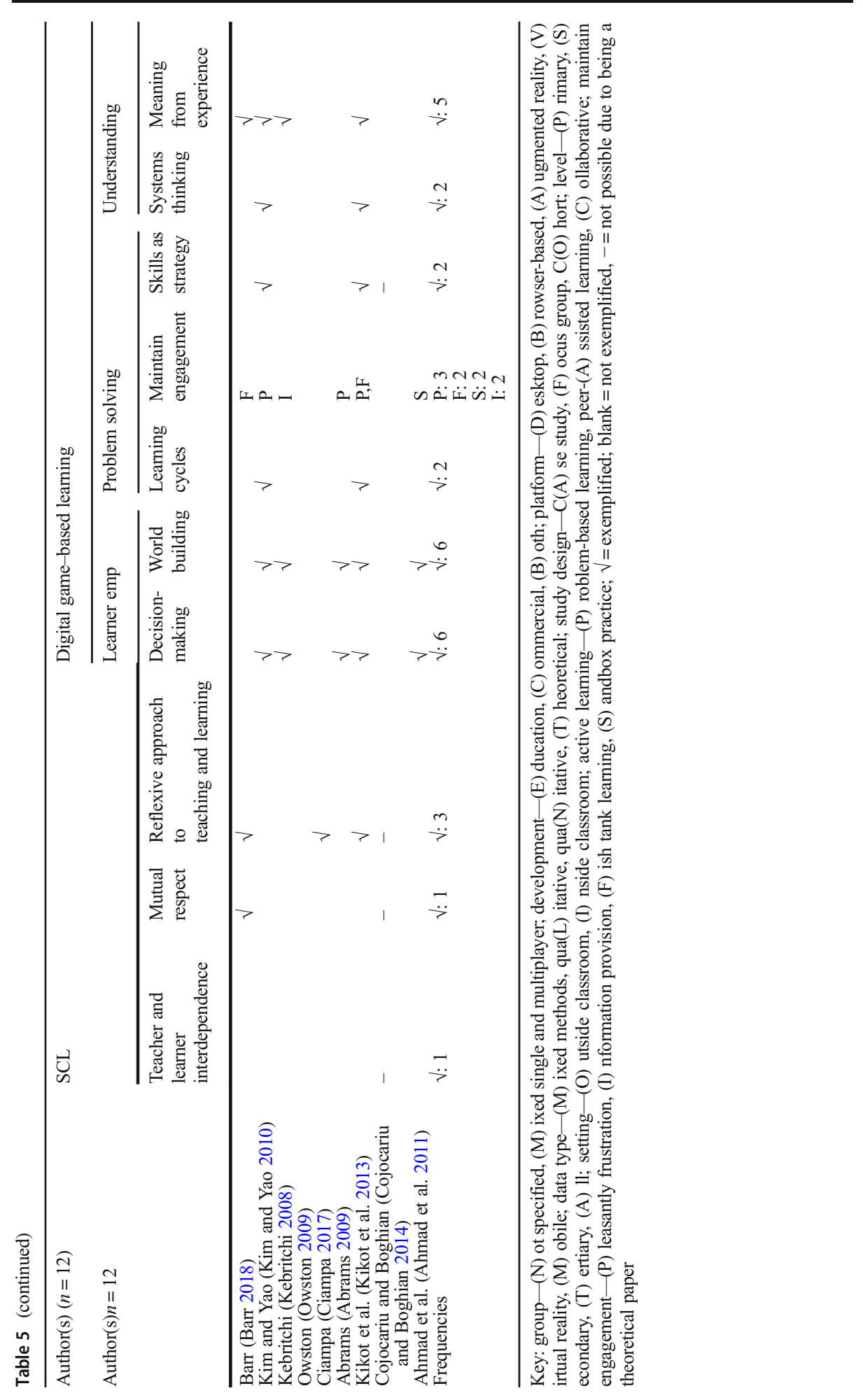


such variation ( $n=5$ (Kikot et al. 2013; Cojocariu and Boghian 2014; Ahmad et al. 2011; Ciampa 2017; Abrams 2009)).

\section{Game type}

Similarly to the single-player category, the majority of studies made use of educational games (Kim and Yao 2010; Owston 2009; Kebritchi 2008; Kikot et al. 2013; Cojocariu and Boghian 2014; Ciampa 2017), while commercial games were used less often (King 2015; Barr 2018; Ahmad et al. 2011; Abrams 2009), e.g. investigating the effect online games such as World of Warcraft may have on learning after school (King 2015).

Again, desktop systems were predominant (King 2015; Ucus 2015; Kennedy-Clark 2011; Kebritchi 2008; Barr 2018; Kikot et al. 2013; Cojocariu and Boghian 2014; Ahmad et al. 2011; Ciampa 2017; Abrams 2009), although more studies considered flexible browser-based games that can be utilised on a number of systems compared to the single-player category (Kim and Yao 2010; Owston 2009). No mobile games were identified.

\section{Study type}

Data collection was primarily qualitative as per the single-player category (King 2015; Ucus 2015; Kennedy-Clark 2011; Barr 2018; Kikot et al. 2013; Ciampa 2017; Abrams 2009), or purely theoretical, presenting new ideas as yet untested or discussing primarily the development of a game or its pedagogical foundations without data on the implementation (Kim and Yao 2010; Owston 2009; Kebritchi 2008; Cojocariu and Boghian 2014; Ahmad et al. 2011). There were no quantitative studies conducted in this category.

Papers were primarily small-sample case studies by design (Ucus 2015; Kennedy-Clark 2011; Barr 2018; Kikot et al. 2013; Ciampa 2017; Abrams 2009), e.g. elementary school teachers' views of game-based learning (Ucus 2015). One study was a cohort study using a group of participants, in this case an after-school programme put together for the purpose of another research study (King 2015). Theoretical papers, as is their nature, did not collect data (Kim and Yao 2010; Owston 2009; Kebritchi 2008; Cojocariu and Boghian 2014; Ahmad et al. 2011). There were no focus group studies.

\section{Setting}

Primary education was the principal area studied (Owston 2009; Ucus 2015; Cojocariu and Boghian 2014; Ciampa 2017), including teachers (Cojocariu and Boghian 2014), (Ciampa 2017) as well as pupils. Few papers looked at secondary level (11-18 years) (King 2015; Kennedy-Clark 2011; Abrams 2009), and focus on narrower age bands within this group, e.g. boys aged 13-16 (King 2015). Similarly, there was limited focus on tertiary-level education (Barr 2018; Kikot et al. 2013; Ahmad et al. 2011). One paper dealt with all age groups (A), categorising pedagogical foundations of a number of educational games without focusing on a particular age group or educational level (Kebritchi 2008). A final paper did not specify the age group addressed and has not been assigned to any of the above categories (Kim and Yao 2010).

Papers mostly utilised settings inside a traditional classroom, per the single-player category (Ucus 2015; Kennedy-Clark 2011; Kikot et al. 2013; Ciampa 2017), including integration of games into an existing university module (Kikot et al. 2013). A small number of studies (King 
2015; Barr 2018; Abrams 2009) took place outside of a school environment, e.g. after school club (King 2015). A final group of papers could not be categorised (Kim and Yao 2010; Kebritchi 2008; Cojocariu and Boghian 2014; Ahmad et al. 2011), e.g. single-game studies not specifying where/when the developed world was accessed (Ahmad et al. 2011), or studies evaluating multiple games without addressing the intended situation of use (Kebritchi 2008).

\section{Student-centred learning}

A small group of papers (Owston 2009; Kebritchi 2008) demonstrate active learning but do not clearly show the usage of any particular sub-techniques - in one instance, this was due to the large volume of games discussed without sufficient detail to identify these (Kebritchi 2008). Problem-based learning was identified in most papers (King 2015; Kim and Yao 2010; Kennedy-Clark 2011; Kikot et al. 2013; Ahmad et al. 2011; Ciampa 2017; Abrams 2009), e.g. investigation of a pre-designed area and its issues within second life (Ahmad et al. 2011). Peer-assisted learning was shown or addressed in some papers, more so than in the single-player category but still only representing a third of studies in this current category (King 2015; Kim and Yao 2010; Kennedy-Clark 2011; Barr 2018). The sole example of collaborative learning within this category invites students to engage, explore and solve the problems presented as a group within a massively multiplayer online setting (Ahmad et al. 2011).

Compared to the single-player category, a relatively small number of papers demonstrated deep learning and understanding (Kebritchi 2008; Kikot et al. 2013; Abrams 2009). More commonly observed within papers were the principles of increased responsibility and accountability (King 2015; Kim and Yao 2010; Kikot et al. 2013; Ciampa 2017), and promoting a sense of autonomy within learners (Kim and Yao 2010; Kennedy-Clark 2011; Kebritchi 2008; Barr 2018; Ahmad et al. 2011; Abrams 2009). However, few papers encompassed teacher and learner interdependence (King 2015), mutual respect (Barr 2018) and a reflexive approach to teaching and learning (Barr 2018; Kikot et al. 2013; Ciampa 2017), echoing the distribution of coverage identified within the single-player category. Again, strong examples existed to evidence the possibilities for integration, such as including opportunities for a teacher to take part in a guiding and participatory role within the game (King 2015), learning communication skills through working together in-game (Barr 2018), and teacher reflection on revisions and improvements to games within special education classrooms.

\section{Digital game-based learning principles}

Learner empowerment Decision-making (Kim and Yao 2010; Kennedy-Clark 2011; Kebritchi 2008; Kikot et al. 2013; Ahmad et al. 2011; Abrams 2009) and world building (Kim and Yao 2010; Kennedy-Clark 2011; Kebritchi 2008; Kikot et al. 2013; Ahmad et al. 2011; Abrams 2009) were observed within a number of studies. In a study on teacher perspectives on games, location/task choice and multiple paths to success were seen as a positive way to provide the same learning outcomes in different ways (Kennedy-Clark 2011). Virtual worlds were seen as a way to allow a high level of interaction in and between created objects and players inside the game world (Ahmad et al. 2011).

Problem solving Learning cycles were demonstrated within a small number of papers compared to the single-player category (Kim and Yao 2010; Kikot et al. 2013), with simulation 
games providing the main example of this, as players are able to observe the unfolding effects of decisions using the information they get "on the fly" to avoid repeating or compounding mistakes and enable success (Kikot et al. 2013).

As per the single-player category, many studies included at least one method of maintaining engagement, often multiple: pleasantly frustrating (Kim and Yao 2010; Kikot et al. 2013; Abrams 2009), information provision (Kennedy-Clark 2011; Kebritchi 2008), fish tank learning (Barr 2018; Kikot et al. 2013) and sandbox learning (Kennedy-Clark 2011; Ahmad et al. 2011). Deployments varied across papers, e.g. limiting consequences to just a time delay as players realise what was and was not effective (Ahmad et al. 2011), or release students from negative consequences early on while they come to understand the basics of managing the virtual business (Kikot et al. 2013).

Skills as strategy was only utilised within a small number of papers, as in the single-player category (Kim and Yao 2010; Kikot et al. 2013). However, a strong example of this is presented through treasure hunt-derived games directly making searching and identification skills a key part of the strategy for winning (Kim and Yao 2010).

Understanding Systems thinking was under-represented (Kim and Yao 2010; Kikot et al. 2013). Simulation games were one example, where players immediately put theory into practice through the game and routes to success and game rules are based on understanding of the educational content (Ahmad et al. 2011). Meaning from experience was the better represented category (Kim and Yao 2010; Kennedy-Clark 2011; Kebritchi 2008; Barr 2018; Kikot et al. 2013). Virtual learning, explored by Kennedy-Clark, addresses this principle, as skills closely linked to in-game experiences enable users to gain a deeper understanding to take beyond the confines of the game (Kennedy-Clark 2011).

\section{Reflective summary}

Findings pertaining to game type were similar to the single player category, but with regard to study type, no quantitative studies were identified with all papers being either qualitative or theoretical with no data presented. Small-sample case study designs were frequently used with only a single cohort study identified, and studies at secondary level were limited. Similar findings were identified with regard to the unequally weighted implementation of SCL tenets and DGBL design principles, although peer-assisted forms of active learning were relatively better represented here in comparison to the single player category, and use of the DGBL design principle of learning cycles was very limited within this category.

\section{Multiplayer}

Table 6 presents studies that involved exclusively multiplayer games; these games include those with a true multiplayer focus ( $\mathrm{G}, n=7$ ) (Dickey 2007; Liu et al. 2011; Yang et al. 2015; Baydas et al. 2015; Stanley and Latimer 2011; Squire and Klopfer 2007; Hung et al. 2018), one played in pairs (P) (Hatton et al. 2008) and those played by multiple players using a single shared terminal (L, $n=4$ ) (Watson et al. 2011; Sung and Hwang 2013; Margino 2013; Yang 2015). 


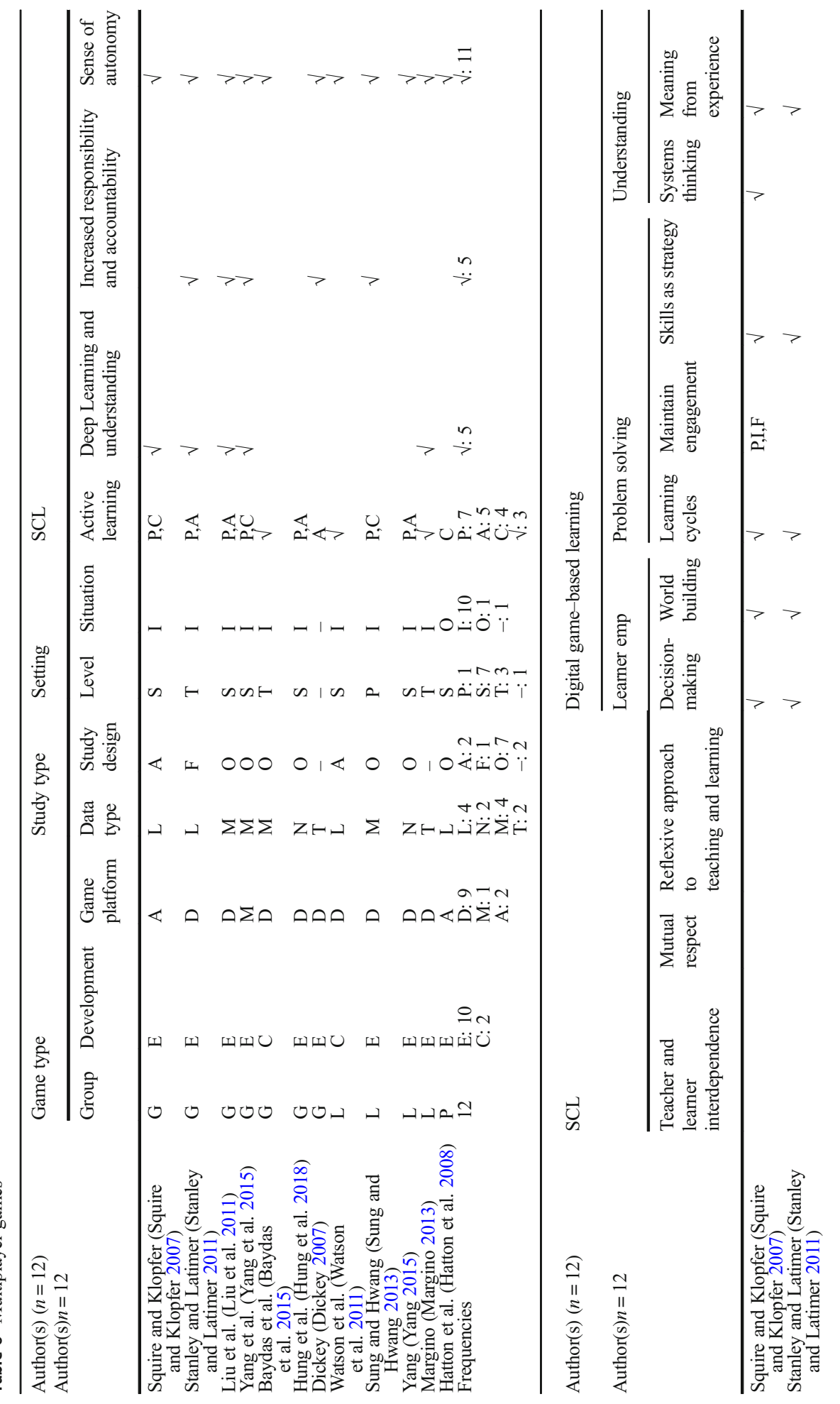




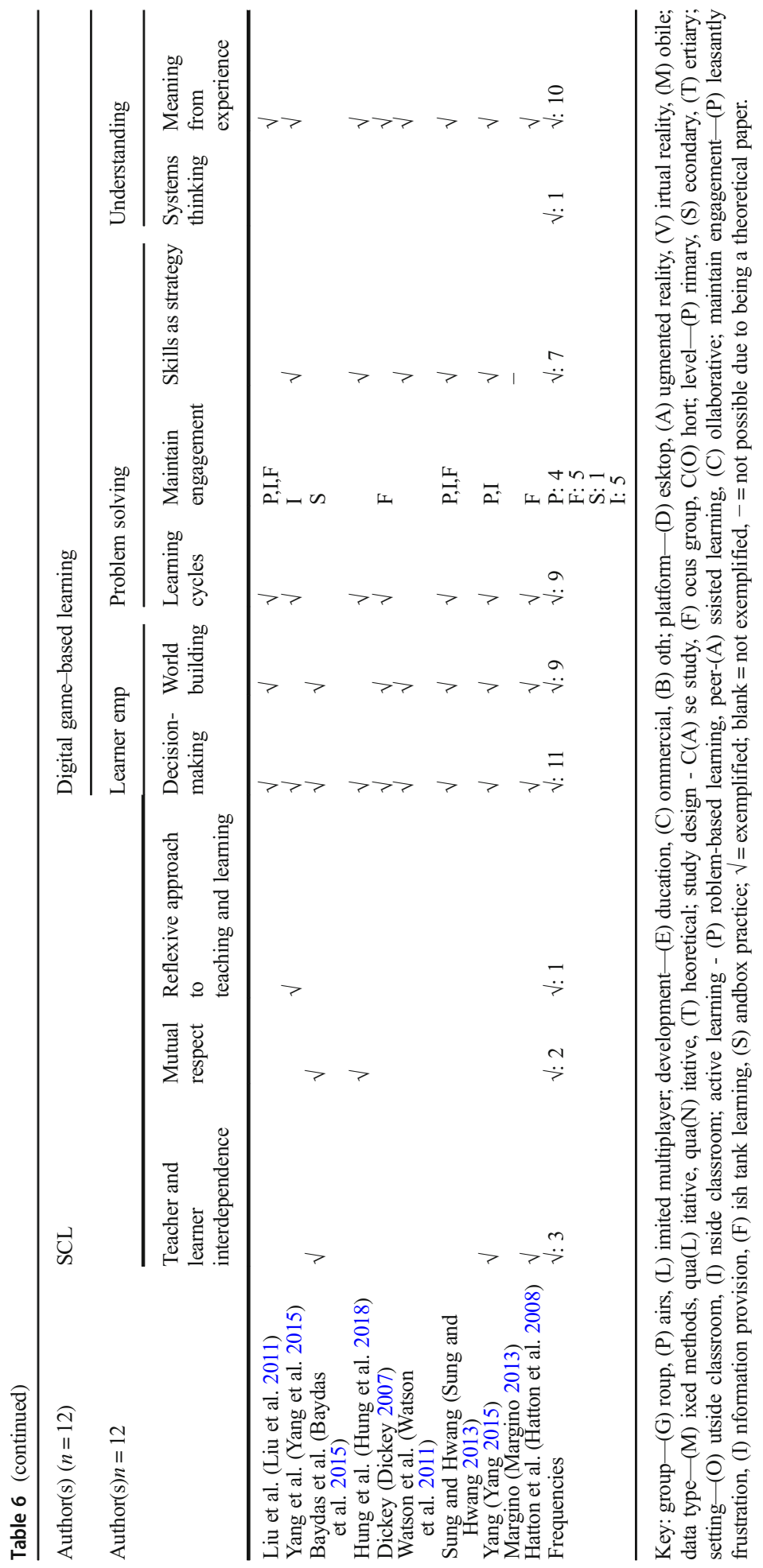




\section{Game type}

As per the other categories, a small number of studies used commercial games as a basis (Baydas et al. 2015; Watson et al. 2011), such as popular massively multiplayer online (MMO) game Second Life (Baydas et al. 2015). The remainder used games primarily designed with educational purposes in mind (Dickey 2007; Liu et al. 2011; Yang et al. 2015; Stanley and Latimer 2011; Squire and Klopfer 2007; Hung et al. 2018; Hatton et al. 2008; Sung and Hwang 2013; Margino 2013; Yang 2015), e.g. 2D educational role-playing game within a science context (Sung and Hwang 2013). Again, the majority (Dickey 2007; Liu et al. 2011; Baydas et al. 2015; Stanley and Latimer 2011; Hung et al. 2018; Watson et al. 2011; Sung and Hwang 2013; Margino 2013; Yang 2015) ran on desktop systems, with one paper suggesting that the power afforded by a desktop system is an important factor in this choice for multiplayer games such as MMOs (Dickey 2007). A small number of studies utilised augmented reality to engage students (Squire and Klopfer 2007; Hatton et al. 2008), such as handheld devices for educating students on environmental sciences out in the field (Squire and Klopfer 2007). Like the other categories, only a single study utilised mobile devices and this was primarily for data access across locations (Yang et al. 2015). There were no browser-based games in this category.

\section{Study type}

Distribution of data types was more mixed for this category, including qualitative data (Stanley and Latimer 2011; Squire and Klopfer 2007; Hatton et al. 2008; Watson et al. 2011) (e.g. observations, interviews, documentary analysis), mixed methods (Liu et al. 2011; Yang et al. 2015; Baydas et al. 2015; Sung and Hwang 2013) and to a more limited extent quantitative data (Yang et al. 2015; Hung et al. 2018). There were fewer entirely theoretical papers compared to the other categories (Dickey 2007; Margino 2013). Study designs also varied. A number of cohort studies were performed (Liu et al. 2011; Yang et al. 2015; Baydas et al. 2015; Hung et al. 2018; Hatton et al. 2008; Sung and Hwang 2013; Yang 2015), with less usage of case studies (Squire and Klopfer 2007; Watson et al. 2011). Like the other categories, focus group studies were very limited (Stanley and Latimer 2011).

\section{Setting}

In contrast to other categories which focused usually on primary education, a single study in the multiplayer category targeted students at the primary level (Sung and Hwang 2013). Instead, most were aimed at secondary (Liu et al. 2011; Yang et al. 2015; Squire and Klopfer 2007; Hung et al. 2018; Hatton et al. 2008; Watson et al. 2011; Yang 2015), typically targeting a subgroup e.g. US middle school students (aged 11-14) (Liu et al. 2011). In contrast to other categories, tertiary students were the focus of a small number of papers (Baydas et al. 2015; Stanley and Latimer 2011; Margino 2013).

Like the other categories, the majority of the studies looked at the use of games inside a traditional classroom (Liu et al. 2011; Yang et al. 2015; Baydas et al. 2015; Stanley and Latimer 2011; Squire and Klopfer 2007; Hung et al. 2018; Watson et al. 2011; Sung and Hwang 2013; Margino 2013; Yang 2015). One study took place outside the normal school environment, using a specially designed facility for augmented reality-based learning to which 
students were invited from school to take part (Hatton et al. 2008). A final theoretical paper did not specifically cover the location the learning was to take place within (Dickey 2007).

\section{Student-centred learning}

Active learning was represented to some degree in all papers; however, the subcategories included within each paper differ. Fewer papers did not specify the delivery method for active learning, compared to other categories (Baydas et al. 2015; Watson et al. 2011; Margino 2013). One such example addresses the potential of digital video games within an area, but does not identify in any game a significant lean towards problem-based learning nor realise peer-based learning beyond the presence of multiple players (Margino 2013).

Many included problem-based learning (Liu et al. 2011; Yang et al. 2015; Stanley and Latimer 2011; Squire and Klopfer 2007; Hung et al. 2018; Sung and Hwang 2013; Yang 2015), with one applying this within an augmented reality platform for both long- and shortterm problems (Squire and Klopfer 2007). A small number of papers included peer-assisted learning aspects (Dickey 2007; Liu et al. 2011; Stanley and Latimer 2011; Hung et al. 2018; Yang 2015), but implementation was strong, e.g. a business-based simulation where students operate in groups, engaging in collective decisions and sharing collective responsibility for these upon their business, as well as permitting between-group competition, allowing actions of other peer groups to be learned from (Yang 2015). A final group of papers included fully realised collaborative elements (Yang et al. 2015; Squire and Klopfer 2007; Hatton et al. 2008; Sung and Hwang 2013), such as multiple groups simultaneously working on aspects within an augmented reality game, with teacher guidance allowing the actions of every student to contribute to group success (Hatton et al. 2008).

Deep learning and understanding was demonstrated in more papers than the mixed category (Liu et al. 2011; Yang et al. 2015; Stanley and Latimer 2011; Squire and Klopfer 2007; Margino 2013), and increased responsibility and accountability also appeared within several studies (Dickey 2007; Liu et al. 2011; Yang et al. 2015; Stanley and Latimer 2011; Sung and Hwang 2013), with MMO games arising again as an example of allowing players to perform individually and as part of a group where players could see and compare their progress (Dickey 2007).

A majority of papers were able to demonstrate or place emphasis on student sense of autonomy while playing (Dickey 2007; Liu et al. 2011; Yang et al. 2015; Baydas et al. 2015; Stanley and Latimer 2011; Squire and Klopfer 2007; Hatton et al. 2008; Watson et al. 2011; Sung and Hwang 2013; Margino 2013; Yang 2015). This tenet was placed under particular emphasis in one study looking at the student's autonomous or unguided experience in learning simulations created for the purpose (Baydas et al. 2015).

Like the other categories, teacher and learner interdependence appeared in a smaller number of multiplayer papers (Baydas et al. 2015; Hatton et al. 2008; Yang 2015), as did mutual respect (Baydas et al. 2015; Hung et al. 2018) and a reflexive approach to teaching and learning (Yang et al. 2015). Yet, some examples of implementation were demonstrated, such as allowing students and teachers to play off each other's ideas and understanding within an augmented reality-based learning module (Hatton et al. 2008), students cooperating to engage in activities, explore and build upon a world directly created by the teacher (Baydas et al. 2015), and a long-term learning study that specifically allowed students to see what effects they were having and adjust their actions and learning to better take part (Yang et al. 2015). 


\section{Digital game-based learning principles}

Learner empowerment As in other categories, decision-making (Dickey 2007; Liu et al. 2011; Yang et al. 2015; Baydas et al. 2015; Stanley and Latimer 2011; Squire and Klopfer 2007; Hung et al. 2018; Hatton et al. 2008; Watson et al. 2011; Sung and Hwang 2013; Yang 2015; Bidin and Ziden 2013) and world building appear in most studies (Dickey 2007; Liu et al. 2011; Baydas et al. 2015; Stanley and Latimer 2011; Squire and Klopfer 2007; Hatton et al. 2008; Watson et al. 2011; Sung and Hwang 2013; Yang 2015). One study highlights the use of many games that speak to both facets of learner empowerment, including civilisation, which allows players to both very fine control over aspects of the country they rule should they desire, and provides a world that responds to any such changes to allow the player to feel they are making a difference (Watson et al. 2011).

Problem solving Again, learning cycles were featured in a majority of papers (Dickey 2007; Liu et al. 2011; Yang et al. 2015; Stanley and Latimer 2011; Squire and Klopfer 2007; Hung et al. 2018; Hatton et al. 2008; Sung and Hwang 2013; Yang 2015), including multiple opportunities to attempt tasks, then see and learn from results, and more difficult goals for achieving students to build upon their skills (Yang 2015).

Similarly, maintaining engagement was featured in the majority of papers, though the subcategories were not evenly spread. Pleasantly frustrating (Liu et al. 2011; Squire and Klopfer 2007; Sung and Hwang 2013; Yang 2015) and information provision (Liu et al. 2011; Yang et al. 2015; Squire and Klopfer 2007; Sung and Hwang 2013; Yang 2015) were well utilised principles, along with fish tank learning (Liu et al. 2011; Squire and Klopfer 2007; Hatton et al. 2008; Sung and Hwang 2013; Dickey 2005). However, only one paper explored the principle of sandbox learning, comparing presence (free reign to explore an area) and absence (close teacher guidance) of this aspect (Baydas et al. 2015). By contrast, skills as strategy appears in many more papers compared to the other player categories (Yang et al. 2015; Stanley and Latimer 2011; Squire and Klopfer 2007; Hung et al. 2018; Watson et al. 2011; Sung and Hwang 2013; Yang 2015).

Understanding Meaning from experience appeared in all but two papers (Dickey 2007; Liu et al. 2011; Yang et al. 2015; Stanley and Latimer 2011; Squire and Klopfer 2007; Hung et al. 2018; Hatton et al. 2008; Watson et al. 2011; Sung and Hwang 2013; Yang 2015), proving to be well-represented as in the other categories. However, systems thinking was very poorly represented, with a single paper using a game with realism as a key goal, organised around the simulation of the skills and ideas it intends to convey and the results of using them (Squire and Klopfer 2007).

\section{Reflective summary}

Findings for game type reflected the other two player engagement categories. For study type, greater use of mixed methods and quantitative data collection methods was employed compared to the mixed category, and only a small number of theoretical papers were identified. Study design was primarily cohort-based, as in the single player category, and usage of case studies was far lower compared to the mixed and single player categories. Again, follow-up 
was limited and interventions usually deployed for a limited time frame. Studies usually focused on older students with just a single paper addressing primary-level age groups. As in the mixed category, peer-assisted forms of active learning were better represented compared to the single player category, although not in all papers. Within this category are the only deployments of SCDGBL interventions with fully realised collaborative elements. Otherwise, findings for implementation of SCL tenets mirrored other player engagement categories. Findings for usage of DGBL design principles were similar to that of the single player category, but the sandbox practice method of maintaining engagement was represented in just a single paper within this category.

\section{Overall summary of literature review findings}

There was a reasonable distribution of study types, although the mixed category for player engagement contained the majority of case study design papers. Use of follow-up periods and post-study evaluation of SCDGBL interventions was limited. While active learning was demonstrated in some form in a majority of papers (Shafie and Ahmad 2010; Shahriarpour 2014; Lin and Lin 2014; Seng and Yatim 2014; Annetta et al. 2013; Neville et al. 2009; Su and Cheng 2013; ter Vrugte et al. 2017) (Baytak and Land 2011; Bowen et al. 2014; Peng et al. 2017; Garcia and Pacheco 2013; Hwang et al. 2013; Hwang et al. 2015; Khamparia and Pandey 2018; Wang et al. 2018; Yang et al. 2010; Liu and Chu 2010; Ameerbakhsh et al. 2018; Kiger et al. 2012; Diah et al. 2012; Monteiro et al. 2011; Norton et al. 2008), less evident was the integration of specific and popular active learning techniques routinely used in student-centred learning, such as problembased and peer-assisted learning. While a number of studies had some level of peerbased learning (King 2015; Kim and Yao 2010; Kennedy-Clark 2011; Barr 2018; Ahmad et al. 2011), there was only one study within this category (Ahmad et al. 2011) that conclusively demonstrated higher-level collaborative and cooperative learning experiences or more engaged peer tutoring.

Few interventions (Baytak and Land 2011; Bate et al. 2014; Hwang et al. 2013; Annetta et al. 2013; Barr 2018; Kikot et al. 2013; Ciampa 2017; Yang et al. 2015) provided deliberate opportunity for or emphasis upon a reflexive approach to teaching and learning, or placed priority on the integration of teachers into a game-based learning experience in a robust manner to promote teacher and learner interdependence (Baytak and Land 2011; Bate et al. 2014; Yang et al. 2010; Kiger et al. 2012; King 2015; Baydas et al. 2015; Hatton et al. 2008; Yang 2015). Mutual respect between teachers and students, and between students is a cornerstone of SCL, yet only a small number of studies make such outcomes a priority in the interventions explored (Baytak and Land 2011; Bate et al. 2014; Barr 2018; Baydas et al. 2015; Hung et al. 2018). Specifically in the mixed category of player engagement, deep learning and understanding was not well explored (Kebritchi 2008; Kikot et al. 2013; Abrams 2009).

While there are a number of studies in Table 3 that aim to fully deploy SCL in a multiplayer context (Dickey 2007; Liu et al. 2011; Yang et al. 2015; Baydas et al. 2015; Stanley and Latimer 2011; Squire and Klopfer 2007; Hung et al. 2018), many papers did not offer a truly multiplayer experience (Hatton et al. 2008; Watson et al. 2011; Sung and Hwang 2013; Margino 2013; Yang 2015). Of these studies, many did not have the group engagement take place within the game environment, instead opting to have a group of students around one terminal (Watson et al. 2011; Sung and Hwang 2013; Margino 2013; Yang 2015) with one 
student taking the role of inputting the group instructions. Despite emerging technologies demonstrating significant potential in the area of education, few studies to date have utilised augmented reality or virtual reality within SCDGBL. A large number of studies using mixed game types were primarily theoretical in nature without data to support them (Kim and Yao 2010; Owston 2009; Kebritchi 2008; Cojocariu and Boghian 2014; Ahmad et al. 2011). Such ideas need to be tested before they can be fully implemented.

The majority of studies reviewed promoted student understanding through meaning from experience. However, the other facet of understanding, systems thinking, which represents pervasive interlinking between game elements and learning outcomes within the game world, was not well represented throughout the literature sample. Although techniques to maintain engagement were widely used across all three player engagement categories, use of sandbox learning, a key principle of many digital games, was extremely limited.

\section{Insights and reflections}

Organising the literature on SCDGBL using the conceptual framework allows identification of which principles highlighted within it are, and are not, forwarded by current research. The conceptual framework gives equal weighting to all the SCL tenets and DGBL principles; therefore, the central finding of this review is that a majority of the interventions claiming to be student-centred do not deliver a full cross section of the SCL experience. This will now be discussed in more detail.

\section{Student-centred learning}

Key SCL principles of teacher and learner interdependence, mutual respect and a reflexive approach to teaching and learning are poorly represented within current SCDGBL offerings, which also encompasses the majority of ideas expressed within theoretical papers, thereby demonstrating that these concepts are also not within the forefront of thinking in this area. An important linkage between these three under-represented tenets within SCDGBL is that they all encompass a "social element" as discussed above. Despite the majority of the SCDGBL literature falling into the single player category, strong examples of implementation of these tenets were demonstrated across all player engagement categories, demonstrating that there may be more to this under-representation warranting discussion.

\section{Active learning}

Although active learning was embraced by the majority of papers presented across all three player engagement modalities, the specific delivery technique for this was frequently not specified or did not incorporate peer elements (e.g. peer-assisted learning, cooperative or collaborative learning), primarily within the single player category (Table 4). While this can explain the limited representation of social elements within that category, even within the mixed and multiplayer categories (Table 5 and Table 6), which had many more instances of peer-assisted, cooperative or collaborative learning, the social elements of SCL were only represented within a small number of papers. This indicates that increasing the number of players within the game experience does not necessarily serve to address all social elements of SCL, without thought and consideration given to game design. 
Many of the "group" and "limited" multiplayer experiences covered in the papers presented (Table 6) were not fully leveraging the potential of interaction with other players to incorporate these social elements of SCL, e.g. building in challenges requiring collaborative or cooperative learning to overcome. Many of these are subsequently isolated experiences within a multiplayer environment, which in some instances restrict student contribution/participation (e.g. single terminal studies). Such approaches risk impacting implementation of other SCL tenets such as deep learning and understanding or even the degree to which active learning is communicated if students are unable to contribute or explore the world directly. Looking to the future, there may be potential to integrate auto-grouping elements as seen in MMO games such as World of Warcraft, where groups can be put together on the fly based on players identified and/or self-defined skills, strengths and needs, in keeping with active learning techniques that involve peers as defined above. Creating fully collaborative, in-game experiences that bring students together within the game client has the potential to combine deep learning and understanding, and the social elements of SCL.

Further, peer-based active learning techniques do not need to be confined to multiplayer games, as demonstrated by one study within the single player engagement category which integrated class discussions before and after interactions with the game (Baytak and Land 2011). Alternatively, an opportunity for students to view others in real time to create peerlearning experiences may allow feedback and learning to flow both ways, with active students demonstrating techniques while student viewers may be able to offer feedback on where to improve (Livsey and Lavender-Stott 2015).

\section{A reflexive approach to teaching and learning}

Few of the games used in interventions were pre-existing commercial games, with many being specifically developed for the research study it was used in. Due to the nature of academic interventions where an aspect of the onus for reflection is taken on by the researcher, there may be less opportunity for teachers and students to take a reflexive approach to their own teaching and learning during deployment of the intervention. Follow-up studies after intervention completion, or extension of an intervention to cross multiple topic areas over a longer period could address some of these issues. This rarely occurred in the papers reviewed; similarly, it is not clear whether these academic interventions went on to be deployed long-term within the chosen setting, thereby allowing teachers and students to take on the reflective role previously assumed by the researcher. While a space still exists to build upon these ideas, the withingames knowledge level required to adapt the experience based on reflection is high e.g. programming and graphic design skills. It is harder for teachers to therefore adapt an intervention to suit their class, even should an opportunity to do so be observed.

\section{Teacher and learner interdependence and mutual respect}

Robust integration of teachers into an active part of the game world may offer the opportunity to both build and build upon the relationship between students and teachers, encompassing the tenets of both teacher and learner interdependence and mutual respect. Reducing the teacher's role to technical support given outside the game interface risks placing the teacher's position below that of the game in terms of importance in delivering student learning which may have longer-term negative outcomes. Teachers should be provided the opportunity to demonstrate skills both in the subject areas and in the game being played. Where teachers may not be 
familiar with the games, they should be open to learning from able students, allowing a role reversal to build respect for both the teacher and student involved.

Drawing from successful commercial games, it may be possible to integrate the teacher as a form of Game Manager, actively managing the game from inside the client and appearing as a presence there, able to interact with students on that level to offer help and rewards that players could ask for or enjoy; this may serve to increase both interdependence and respect as the teacher's presence expands in a positive manner. While it could be argued that greater embedding of teacher and learner interdependence may come at the price of independent learning (Baydas et al. 2015), the study achieving this demonstrated that similar outcomes can still be achieved, although further studies to reinforce this would be helpful.

\section{Digital game-based learning}

All three areas of DGBL were well represented within the SCDGBL literature reviewed, but the component principles within each of those areas were not evenly represented. This would suggest that some DGBL principles are not as well utilised to deliver SCL tenets within current SCDGBL interventions. Possible explanations for this are discussed below.

\section{Systems thinking and skills as strategy}

Systems thinking is a DGBL principle linked to deep learning and understanding, sense of autonomy, and problem-based learning techniques within active learning (Table 3). Despite these SCL tenets being well represented across all three player engagement categories, systems thinking did not appear to be utilised as a vehicle for delivering them, with just 8 studies within the literature pool discussing or implementing this. This may be due to the difficulties in implementing systems thinking within an educational game design, compared to other DGBL design principles conceptually linked to the same tenets (Table 3).

An effective implementation closely ties game world, mechanics and learning outcomes it seeks to deliver. A poorly integrated or superficial educational layer damages systems thinking, as students dissociate the skills learned through gameplay from those clearly intended to have educational value. It also impacts skills as strategy, as students who pick up skills or knowledge from the educational layer become unable to use these to effectively strategise and progress through the game. As discussed in the introduction, quality of the learning process affects quality of learning outcomes. If learning outcomes become something clearly discrete to the player from their ability to progress in the game, the worst case would be seeing the learning outcomes as an obvious impediment to game progress rather than an integral part of the experience, breaking immersion and compromising benefits associated with deep learning and understanding.

Such impacts can be more keenly felt within multiplayer environments, where the expectation is that interactions with players, whether cooperative or competitive, are uninterrupted. As such, the greater representation of skills as strategy within the multiplayer category may be attributed to the need for greater finesse in design and development to preserve a good player experience in deployment. Although few studies made use of commercial games as vehicles for learning, use of these "off the shelf" or with minimal adaptation is one situation that runs the risk of invoking the worst case of poor immersion. While systems thinking is deeply embedded within many commercial games, this teaches mastery of the game, as opposed to 
understanding of the educational content that is sought to be delivered. It is therefore important to consider how learning outcomes can be not just surface level but foundational elements of how the fictional world functions.

World building was well integrated into many SCDGBL offerings reviewed, embracing this as developers enable the creation of not just a game but a coherent learning world that the game takes place within. Further studies exploring the impact of deeper integration of world building could be helpful to better establish what kind of contribution a comprehensive implementation of systems thinking and skills as strategy could make to SCDGBL interventions.

\section{Sandbox learning}

Sandbox learning is utilised significantly in traditional gaming for player learning and practice in a threat free environment. Games such as Minecraft offer the ability to play the entire game in this way, making it popular in education contexts (Nebel et al. 2016), while players of multiplayer team games such as League of Legends pushed for developers to give them such a tool (Reddit 2015). Few games reviewed fully realised this feature, limiting user approach to each of the game's elements to test out their abilities. While this may be difficult to achieve depending upon the game type and desired learning outcomes, allowing students to revisit and explore concepts, practising and developing skills is an important enabler of the underrepresented SCL tenet a reflexive approach to teaching and learning, and opens up further usage of games as revision tools.

\section{Use of emerging technologies}

Systems utilised within interventions were often old/established, e.g. desktop systems, with limited attention paid to emerging technologies despite their promise. It has been suggested that the power afforded by a desktop system is an important factor in choice, particularly for multiplayer games such as MMOs (Dickey 2007). Although questions remain over their suitability for deployment in school settings, which comprise a major proportion of these studies, the integration of emerging technologies could be further improved within a student-centred context. Further studies to investigate the effect of such technologies from a student-centred perspective could establish to whether the potential benefits emerging technologies offer to game design carry over to learning outcomes and other benefits within a student-centred environment. Although no longer an emerging technology, mobile as a platform was not utilised by the majority of papers. This may be because of concerns over practical deployment on this platform (e.g. device access, interoperability and cost) (Bidin and Ziden 2013).

\section{General discussion}

This review highlighted the need for better-quality studies and deeper evaluation of SCDGBL interventions. Many identified papers were case studies, limiting generalisability, or theoretical papers lacking implementation. There were few longitudinal studies or use of follow-up to determine impact of SCDGBL interventions beyond "research conditions", and exploration of the impact of interventions upon measurable learning outcomes, e.g. class tests, was often not carried out. These findings are supported by another previously published review that 
encompassed both digital and non-digital educational games without having a SCL focus (Petri and von Wangenheim 2016). Testing interventions on larger cohorts may provide more broadly applicable quantitative data, which may better establish the effectiveness of pioneered techniques. While low-reach studies are valuable to establish viability and yield helpful qualitative insights, the area of education can be broad, with significant differences between cohorts based on area. The general viability of techniques would be better spoken to with a larger cohort that cuts across demographics.

\section{Recommendations}

This paper demonstrated effective use of a conceptual framework developed from a thematic analysis of the SCDGBL literature to organise, present and evaluate SCDGBL interventions or discussion papers. The framework gives equal weighting to both the key tenets of SCL and design principles for DGBL. In doing so, its use has demonstrated that not only do many SCDGBL offerings show poor integration of the social elements of SCL, but also that certain DGBL design principles have received only limited implementation and evaluation of their ability to deliver SCL tenets. Based on the evaluation of the research literature presented in this study, the following recommendations for the future design of SCDGBL interventions are proposed:

1) Greater use of follow-up within study designs could capture reflections upon teaching and learning experiences on the part of students and teachers. This would allow effective assessment of longer-term learning effects as well as providing more opportunity to assess the integration of a reflexive approach to teaching and learning.

2) Longer study durations to utilise a game-based format for multiple topic areas would enable reflection upon progression through these areas. It may also allow the normalisation of game-based learning within a course which could form an interesting basis for future study, in contrast to discrete, constrained interventions.

3) Increasing the number of cohort studies across all player engagement categories may provide more broadly applicable data, which may better establish the effectiveness and feasibility of pioneered techniques by cutting across demographics.

4) Greater involvement of teachers within game environments in an active role should be considered as an opportunity to promote the SCL areas of interdependence and mutual respect.

5) Promote opportunities for role reversal in allowing students skilled at gaming to take on a demonstrating or leadership role, along with integrating cooperative gameplay to build mutual respect between teachers and students.

6) Better integration of emerging technologies within interventions would allow deeper evaluation of the impact of the use of these technologies upon the student-centred learning experience.

7) A number of papers presented SCDGBL ideas within purely theoretical discussion; such papers should be accompanied or followed up by studies implementing or evaluating the ideas explored. While sharing ideas is important, it is necessary to explore these ideas in practice to identify those worth pursuing.

8) Deeper integration of learning outcomes into world building at an early stage would reduce instances of broken immersion and promote systems thinking, thereby enabling use of skills as strategy and enhancing deep learning and understanding. 
9) Offering learners a role to play within a game could enhance player identity and meaning from experience. As players engage with this role, the learning becomes more personal to them player and helps facilitate deep learning and understanding.

10) Deeper integration of peer-based active learning techniques, even within single player interventions, can provide a focus for discussion and engagement, delivering more comprehensively on the social aspects of student-centred learning to deepen immersion and enhance learning outcomes.

11) Further deployment of sandbox learning design principles would enable students to practise their skills, allowing greater use of games as a revision tool and promoting a reflexive attitude to teaching and learning, as students are given tools to explore and learn at their own pace.

\section{Conclusions}

Through this study, a conceptual framework of student-centred digital game-based learning is presented, derived from and used to classify a range of literature published between 2007 and 2018. The themes presented within the conceptual framework were derived from a thematic template analysis and comprise a logical, systematic method of categorising and classifying the literature.

SCDGBL interventions were stratified according to the conceptual framework and presented across three player engagement categories: single player interventions isolate the learner on their own within a game world and present learning as an individual process, mixed interventions made use of different games or different engagement methods with varying or unspecified player numbers and multiplayer interventions engage multiple learners in the same game world at once. Within these categories, the nature of the games designed and deployed and the student-centred learning tenets delivered was explored, categorising educational content and delivery of SCDGBL offerings according to the conceptual framework, which conceptually linked the design principles of digital game-based learning and the seven tenets of studentcentred learning.

Key findings from this process include a strong focus within student-centred digital game-based learning literature on certain SCL elements such as active learning, deep learning and understanding, and developing a student's sense of autonomy and increased responsibility and accountability, most often presented in single player games. With this focus, a number of "social" SCL elements were found to be less well integrated, particularly areas such as mutual respect, teacher and learner interdependence and developing reflexive attitudes to learning and teaching. In addition to these, the utilisation of true multiplayer gaming involving either other students or teachers was found to be lacking. Emerging technologies that could promote innovative collaborative or cooperative learning to address such elements were utilised in a very limited fashion within studies reviewed, despite their popular deployment for leisure gaming.

Gee's principles of good game design have been explored over time and provide a window through which to examine the literature on SCDGBL, highlighting the common groups of techniques games use to teach players. A lack of attention to a number of these principles may indicate areas future educational games may look to further both engage and teach players. The areas of skills as strategy and systems thinking imply a level of integrated world building within game design which may form one area to explore. Further integration of principles such 
as learning cycles may offer an opportunity to deliver effective learning at a player's own pace. Taking an approach early on in game design that recognises the DGBL principles through which a game seeks to realise its educational content in an educational context may allow games to, through gameplay, story and other aspects, provide a better rounded experience to deliver better learning outcomes. These principles require consideration early on in design, demanding that educational use be as core to the game as other aspects, but do not need to and should not come at the cost of making a bad game. Games developed in future should seek to embrace the potential of these principles, making good on the promise of "Good Video Games, Good Learning" made by Gee.

While student-centred digital game-based learning is an active research area, there remains a need to tie together more tightly the design of such games with existing research on how students learn. Without an understanding of the learning elements involved in both the games presented and the student's existing teaching and learning environment, it may be difficult to identify the full value of digital game-based learning techniques. Future studies may benefit from a more thorough exploration of all tenets of SCL, including those more socially focused such as mutual respect and teacher and learner interdependence. Use of DGBL design principles to deliver such tenets may offer the potential to more fully realise the benefits of student-centred learning through digital video games, and to develop games that can be better utilised in the classrooms of the future.

Open Access This article is distributed under the terms of the Creative Commons Attribution 4.0 International License (http://creativecommons.org/licenses/by/4.0/), which permits unrestricted use, distribution, and reproduction in any medium, provided you give appropriate credit to the original author(s) and the source, provide a link to the Creative Commons license, and indicate if changes were made.

\section{References}

Abdul Jabbar, A. I., \& Felicia, P. (2015). Gameplay engagement and learning in game-based learning: A systematic review. Review of Educational Research, 85(4), 740-779.

Abrams, S. S. (2009). A gaming frame of mind: Digital contexts and academic implications. Educational Media International, 46(4), 335-347.

Ahmad, N. S. H. N., Wan, T. R., \& Jiang, P. (2011). Immersive environment courseware evaluation. ProcediaSocial and Behavioral Sciences, 15, 1667-1676.

Ameerbakhsha, O., Maharaja, S., Hussaina, A., \& McAdam, B. (2018). A comparison of two methods of using a serious game for teaching marine ecology in a university setting. International Journal of Human-Computer Studies, 127, 181-189.

Ames, C. (1992). Classrooms: Goals, structures, and student motivation. Journal of Educational Psychology, 84(3), 261.

Annetta, L. A., et al. (2013). Science teacher efficacy and extrinsic factors toward professional development using video games in a design-based research model: The next generation of STEM learning. Journal of Science Education and Technology, 22(1), 47-61.

Attard, A., Di Iorio, E., Geven, K., \& Santa, R. (2010). Time for a new paradigm in education: student-centred learning. In A. Attard (Ed.), (pp. 1-4). Bruxelles, Belgium: European Students Union. https://www.esu-online. org/wp-content/uploads/2016/07/100814-SCL.pdf. Accessed 22/01 2018.

Baltra, A. (1990). Language learning through computer adventure games. Simulation \& Gaming, 21(4), 445-452.

Barr, M. (2018). Student attitudes to games-based skills development: Learning from video games in higher education. Computers in Human Behavior, 80, 283-294.

Barrows, H. S. (1996). Problem-based learning in medicine and beyond: A brief overview. New Directions for Teaching and Learning, 1996(68), 3-12.

Bate, F., MacNish, J., \& Males, S. (2014). The politics of gaming in schools: A sociocultural perspective from Western Australia. Learning, Media and Technology, 39(3), 306-327. 
Baydas, O., et al. (2015). Retention and flow under guided and unguided learning experience in 3D virtual worlds. Computers in Human Behavior, 44, 96-102.

Baytak, A., \& Land, S. M. (2011). An investigation of the artifacts and process of constructing computers games about environmental science in a fifth grade classroom. Educational Technology Research and Development, 59(6), 765-782.

Bidin, S., \& Ziden, A. A. (2013). Adoption and application of mobile learning in the education industry. Procedia-Social and Behavioral Sciences, 90, 720-729.

Bishop, J. L., \& Verleger, M. A. (2013). The flipped classroom: A survey of the research. In ASEE National Conference Proceedings. Atlanta: GA.

Bonk, C. J., \& Cunningham, D. J. (1998). Searching for learner-centered, constructivist, and sociocultural components of collaborative educational learning tools. In K. S. K. Curtis Jay Bonk (Ed.), Electronic collaborators: Learner-centered technologies for literacy, apprenticeship, and discourse (1 ed., Vol. 25, pp. 25-50). the University of Michigan: L. Erlbuam Associates.

Boutsika, E. (2014). Kinect in education: A proposal for children with autism. Procedia Computer Science, 27, $123-129$.

Bowen, E., et al. (2014). "It's like you're actually playing as yourself”: Development and preliminary evaluation of 'Green Acres High', a serious game-based primary intervention to combat adolescent dating violence+. Psychosocial Intervention, 23(1), 43-55.

Bruffee, K. A. (1995). Sharing our toys: Cooperative learning versus collaborative learning. Change: The Magazine of Higher Learning, 27(1), 12-18.

Ciampa, K. (2017). Building bridges between technology and content literacy in special education: Lessons learned from special educators' use of integrated technology and perceived benefits for students. Literacy Research and Instruction, 56(2), 85-113.

Clements, D. H., \& Battista, M. T. (1990). Constructivist learning and teaching. Arithmetic Teacher, 38(1), 34-35.

Cojocariu, V.-M., \& Boghian, I. (2014). Teaching the relevance of game-based learning to preschool and primary teachers. Procedia-Social and Behavioral Sciences, 142, 640-646.

Corno, L. (1992). Encouraging students to take responsibility for learning and performance. The Elementary School Journal, 93(1), 69-83.

Crabtree, B. F., \& Miller, W. F. (1992). A template approach to text analysis: developing and using codebooks. Research methods for primary care, Vol. 3. Doing qualitative research, 3, 93-109.

Del Blanco, Á., et al. (2010). Integrating adaptive games in student-centered virtual learning environments. International Journal of Distance Education Technologies (IJDET), 8(3), 1-15.

Diah, N. M., et al. (2012). Adaptation of environmental anticipation in educational computer game. ProcediaSocial and Behavioral Sciences, 42, 74-81.

Dickey, M. D. (2005). Engaging by design: How engagement strategies in popular computer and video games can inform instructional design. Educational Technology Research and Development, 53(2), 67-83.

Dickey, M. D. (2007). Game design and learning: A conjectural analysis of how massively multiple online roleplaying games (MMORPGs) foster intrinsic motivation. Educational Technology Research and Development, 55(3), 253-273.

Din, F.S. and F. Wheatley. 2007 A literature review of the student-centered teaching approach: National implications. in National Forum of Teacher Education Journal.

Doolittle, P.E., 1995. Understanding cooperative learning through Vygotsky's zone of proximal development.

Fereday, J., \& Muir-Cochrane, E. (2006). Demonstrating rigor using thematic analysis: A hybrid approach of inductive and deductive coding and theme development. International Journal of Qualitative Methods, 5(1), 80-92.

Gabel, D. L., \& Bunce, D. M. (1994). Research on problem solving: Chemistry. Handbook of research on science teaching and learning, 11, 301-326.

Garcia, I., \& Pacheco, C. (2013). A constructivist computational platform to support mathematics education in elementary school. Computers \& Education, 66, 25-39.

Gee, J. P. (2003). What video games have to teach us about learning and literacy. Computers in Entertainment (CIE), 1(1), 20-20.

Gee, J. P. (2005). Learning by design: Good video games as learning machines. E-Learning and Digital Media, 2(1), 5-16.

Hamari, J., et al. (2016). Challenging games help students learn: An empirical study on engagement, flow and immersion in game-based learning. Computers in Human Behavior, 54, 170-179.

Hatton, S., D. Birchfield, and M.C. Megowan-Romanowicz, 2008. Learning metaphor through mixed-reality game design and game play. In Proceedings of the 2008 ACM SIGGRAPH symposium on Video games. ACM.

Hung, C.-Y., Sun, J. C.-Y., \& Liu, J.-Y. (2018). Effects of flipped classrooms integrated with MOOCs and gamebased learning on the learning motivation and outcomes of students from different backgrounds. Interactive Learning Environments, 1-19. https://doi.org/10.1080/10494820.2018.1481103. 
Hwang, G.-J., Yang, L.-H., \& Wang, S.-Y. (2013). A concept map-embedded educational computer game for improving students' learning performance in natural science courses. Computers \& Education, 69, 121-130.

Hwang, G.-J., Chiu, L.-Y., \& Chen, C.-H. (2015). A contextual game-based learning approach to improving students' inquiry-based learning performance in social studies courses. Computers \& Education, 81, 13-25.

Kebritchi, M. (2008). Examining the pedagogical foundations of modern educational computer games. Computers \& Education, 51(4), 1729-1743.

Kennedy-Clark, S. (2011). Pre-service teachers' perspectives on using scenario-based virtual worlds in science education. Computers \& Education, 57(4), 2224-2235.

Kern, E. L., \& Carpenter, J. R. (1986). Effect of field activities on student learning. Journal of Geological Education, 34(3), 180-183.

Khamparia, A., \& Pandey, B. (2018). Effects of visual map embedded approach on students learning performance using Briggs-Myers learning style in word puzzle gaming course. Computers \& Electrical Engineering, 66, 531-540.

Kiger, D., Herro, D., \& Prunty, D. (2012). Examining the influence of a mobile learning intervention on third grade math achievement. Journal of Research on Technology in Education, 45(1), 61-82.

Kikot, T., et al. (2013). Simulation games as tools for integrative dynamic learning: The case of the management course at the University of Algarve. Procedia Technology, 9, 11-21.

Kim, D. W., \& Yao, J. (2010). A treasure hunt model for inquiry-based learning in the development of a webbased learning support system. J. UCS, 16(14), 1853-1881.

King, E. M. (2015). Designing after-school learning using the massively multiplayer online role-playing game. Theory Into Practice, 54(2), 128-135.

Krahenbuhl, K. S. (2016). Student-centered education and constructivism: Challenges, concerns, and clarity for teachers. The Clearing House: A Journal of Educational Strategies, Issues and Ideas, 89(3), 97-105.

Lea, S. J., Stephenson, D., \& Troy, J. (2003). Higher education students' attitudes to student-centred learning: beyond educational bulimia? Studies in Higher Education, 28(3), 321-334.

Lin, H.-W., \& Lin, Y.-L. (2014). Digital educational game value hierarchy from a learners' perspective. Computers in Human Behavior, 30, 1-12.

Liu, T.-Y., \& Chu, Y.-L. (2010). Using ubiquitous games in an English listening and speaking course: Impact on learning outcomes and motivation. Computers \& Education, 55(2), 630-643.

Liu, M., et al. (2011). A study of learning and motivation in a new media enriched environment for middle school science. Educational Technology Research and Development, 59(2), 249-265.

Livsey, K., \& Lavender-Stott, E. (2015). Impact of vicarious learning through peer observation during simulation on student behavioural measures. Focus on Health Professional Education: A Multi-disciplinary Journal, 16(4), 64.

Margino, M. (2013). Revitalizing traditional information literacy instruction: Exploring games in academic libraries. Public Services Quarterly, 9(4), 333-341.

Marginson, S. (2006). Dynamics of national and global competition in higher education. Higher Education, 52(1), 1-39.

Monteiro, M., Corredoura, A., Candeias, M., Morais, P., \& Diniz, J. (2011). Central Hospital-Master of Resuscitation: An immersive learning approach. In Serious Games and Applications for Health (SeGAH), 2011 IEEE 1st International Conference on, Braga, Portugal, 16-18 Nov. 20112011 (pp. 1-4). Piscataway, New Jersey, United States: IEEE. https://doi.org/10.1109/SeGAH.2011.6165438.

Motschnig-Pitrik, R., \& Holzinger, A. (2002). Student-centered teaching meets new media: Concept and case study. Educational Technology \& Society, 5(4), 160-172.

Nebel, S., Schneider, S., \& Rey, G. D. (2016). Mining learning and crafting scientific experiments: A literature review on the use of minecraft in education and research. Journal of Educational Technology \& Society, $19(2), 355$

Neville, D. O., Shelton, B. E., \& McInnis, B. (2009). Cybertext redux: Using digital game-based learning to teach L2 vocabulary, reading, and culture. Computer Assisted Language Learning, 22(5), 409-424.

Nichols, J. D., \& Miller, R. B. (1994). Cooperative learning and student motivation. Contemporary Educational Psychology, 19(2), 167-178.

Norton, C., et al. (2008). Development and deployment of an immersive learning environment for enhancing process systems engineering concepts. Education for Chemical Engineers, 3(2), e75-e83.

Owston, R. D. (2009). Comments on Greenhow, Robelia, and Hughes: Digital immersion, teacher learning, and games. Educational Researcher, 38(4), 270-273.

Peng, C., Cao, L., \& Timalsena, S. (2017). Gamification of Apollo lunar exploration missions for learning engagement. Entertainment Computing, 19, 53-64.

Petri, G., \& von Wangenheim, C. G. (2016). How to evaluate educational games: A systematic. Journal of Universal Computer Science, 22(7), 992-1021. 
Reddit (2015). Riot's "Sandbox Mode" reply makes it obvious how little they seem to understand the competitive setting of their game. Discussion and Feedback. Riot Games. https://www.reddit. com/r/leagueoflegends/comments/3fxo33/riots_sandbox_mode_reply_makes_it_obvious_how/. Accessed 23/05 2018.

Reichel, M., \& Ramey, M. A. (1987). Conceptual frameworks for bibliographic education: Theory into practice. CO: Libraries Unlimited Littleton.

Rocca, K. A. (2010). Student participation in the college classroom: An extended multidisciplinary literature review. Communication Education, 59(2), 185-213.

Rohrbeck, C. A., et al. (2003). Peer-assisted learning interventions with elementary school students: A metaanalytic review. Journal of Educational Psychology, 95(2), 240.

Samaniego Erazo, G. N., Esteve-González, V., \& Vaca, B. (2015). Teaching and Learning in digital worlds: strategies and issues in higher education. In M. B. Mercè Gisbert (Ed.), Teaching and Learning in Digital World: Strategies and Issues in Higher Education (pp. 129-136). Catalunya.: Publicacions Universitat Rovira.

Seel, N.M., 2011. Encyclopedia of the sciences of learning. Springer Science \& Business Media. 6535.

Seng, W. Y., \& Yatim, M. H. M. (2014). Computer game as learning and teaching tool for object oriented programming in higher education institution. Procedia-Social and Behavioral Sciences, 123, 215-224.

Shafie, A., \& Ahmad, W. F. W. (2010). Design and heuristic evaluation of mathQuest: A role-playing game for numbers. Procedia-Social and Behavioral Sciences, 8, 620-625.

Shahriarpour, N. (2014). On the effect of playing digital games on Iranian intermediate efl learners' motivation toward learning English vocabularies. Procedia-Social and Behavioral Sciences, 98, 1738-1743.

So, W. W. (2012). Creating a framework of a resource-based e-learning environment for science learning in primary classrooms. Technology, Pedagogy and Education, 21(3), 317-335.

Squire, K., \& Klopfer, E. (2007). Augmented reality simulations on handheld computers. The Journal of the Learning Sciences, 16(3), 371-413.

Stanley, D., \& Latimer, K. (2011). 'The Ward': A simulation game for nursing students. Nurse Education in Practice, $11(1), 20-25$.

Su, C.-H., \& Cheng, C.-H. (2013). A mobile game-based insect learning system for improving the learning achievements. Procedia-Social and Behavioral Sciences, 103, 42-50.

Sung, H.-Y., \& Hwang, G.-J. (2013). A collaborative game-based learning approach to improving students' learning performance in science courses. Computers \& Education, 63, 43-51.

Sungur, S., \& Tekkaya, C. (2006). Effects of problem-based learning and traditional instruction on self-regulated learning. The Journal of Educational Research, 99(5), 307-320.

Taber, K. S. (2009). The Negative Heuristic and Criticisms of Constructivism in Science Education. In Progressing science education: Constructing the scientific research programme into the contingent nature of learning science (Vol. 37, pp. 202-207). Berlin, Germany: Springer Science \& Business Media.

Tang, S., Hanneghan, M., \& El Rhalibi, A. (2009). Introduction to games-based learning. In T. Connolly (Ed.), Games-based learning advancements for multi-sensory human computer interfaces: Techniques and effective practices (1 ed., pp. 1-17). Pennsylvania, United States: IGI Global.

ter Vrugte, J., et al. (2017). Computer game-based mathematics education: Embedded faded worked examples facilitate knowledge acquisition. Learning and Instruction, 50, 44-53.

The Scottish Government (2009). Curriculum for Excellence, Building the Curriculum 4: Skills for learning, skills for life and skills for work (Education Scotland, Trans.). (pp. 7-39). Edinburgh: The Scottish Government. https://scqf.org.uk/media/1142/btc4_skills_tcm4-569141.pdf. Accessed 27/11 2017.

Topping, K. J. (1996). The effectiveness of peer tutoring in further and higher education: A typology and review of the literature. Higher Education, 32(3), 321-345.

Ucus, S. (2015). Elementary school teachers' views on game-based learning as a teaching method. ProcediaSocial and Behavioral Sciences, 186, 401-409.

Urdan, T., \& Schoenfelder, E. (2006). Classroom effects on student motivation: Goal structures, social relationships, and competence beliefs. Journal of School Psychology, 44(5), 331-349.

Wang, S.-Y., et al. (2018). A microworld-based role-playing game development approach to engaging students in interactive, enjoyable, and effective mathematics learning. Interactive Learning Environments, 26(3), 411-423.

Ward-Penny, R. (2010). Application and transfer: mathematics and the science subjects. In Cross-Curricular Teaching and Learning in the Secondary School... Mathematics (1 ed., pp. 31-43). London: Routledge.

Watson, W. R., Mong, C. J., \& Harris, C. A. (2011). A case study of the in-class use of a video game for teaching high school history. Computers \& Education, 56(2), 466-474.

Wijnia, L., Loyens, S. M., \& Derous, E. (2011). Investigating effects of problem-based versus lecture-based learning environments on student motivation. Contemporary Educational Psychology, 36(2), 101-113.

Wright, G. B. (2011). Student-centered learning in higher education. International Journal of Teaching and Learning in Higher Education, 23(1), 92-97. 
Yang, Y.-T. C. (2015). Virtual CEOs: A blended approach to digital gaming for enhancing higher order thinking and academic achievement among vocational high school students. Computers \& Education, 81, 281-295.

Yang, J. C., Chen, C. H., \& Jeng, M. C. (2010). Integrating video-capture virtual reality technology into a physically interactive learning environment for English learning. Computers \& Education, 55(3), 1346-1356.

Yang, Y.-T. C., et al. (2015). Technology-enhanced game-based team learning for improving intake of food groups and nutritional elements. Computers \& Education, 88, 143-159.

Publisher's note Springer Nature remains neutral with regard to jurisdictional claims in published maps and institutional affiliations. 